\title{
A critical review on antibiotics and hormones in swine wastewater: Water pollution problems and control approaches
}

Dongle Cheng ${ }^{\mathrm{a}}$, Huu Hao Ngo ${ }^{\mathrm{a}, b^{*}}$, Wenshan Guo ${ }^{\mathrm{a}}$, Soon Woong Chang ${ }^{\mathrm{c}}$ Dinh Duc Nguyen ${ }^{\mathrm{c}, \mathrm{d}}$, Yiwen Liu ${ }^{\mathrm{a}}$, Qin Wei ${ }^{\mathrm{e}}$, Dong Wei ${ }^{\mathrm{f}}$

${ }^{a}$ Centre for Technology in Water and Wastewater, School of Civil and Environmental Engineering, University of Technology Sydney, Sydney, NWS 2007, Australia

${ }^{b}$ NTT Institute of Hi-Technology, Nguyen Tat Thanh University, Ho Chi Minh City, Viet Nam

${ }^{c}$ Department of Environmental Energy Engineering, Kyonggi University, 442-760, Republic of Korea ${ }^{d}$ Institution of Research and Development, Duy Tan University, Da Nang, Vietnam

${ }^{e}$ Key Laboratory of Chemical Sensing and Analysis in Universities of Shandong, School of Chemistry and Chemical Engineering, University of Jinan, Jinan 250022, PR

China

${ }^{f}$ School of Water Conservancy and Environment, University of Jinan, Jinan 250022, PR China

*Corresponding authors: H. H. Ngo; E-mail address: ngohuuhao121@gmail.com

Graphical abstract 


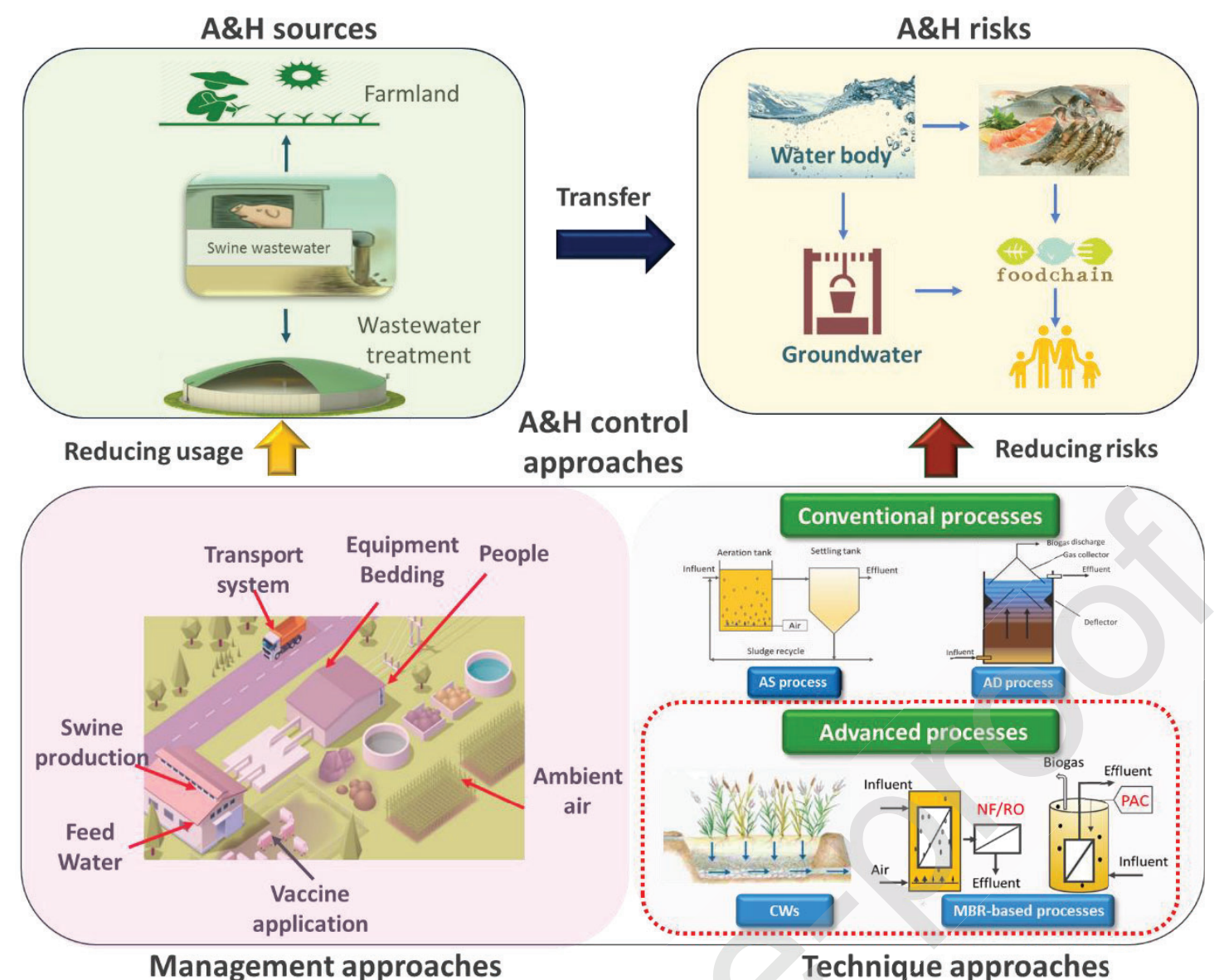

\section{Highlights}

- Water polluted by swine wastes contains higher levels of antibiotics and hormones.

- Contaminated water pose high threat to the organisms and human health.

- Developing antibiotic alternatives is necessary to eliminate antibiotic risks.

- Enhancing vaccination technology and biosecurity application are essential.

- Combination of bioprocesses and AOPs is expected to be a promising technology. 


\section{Abstract}

Swine wastewater (SW) is an important source of antibiotics and hormones (A\&H) in the environment due to their large-scale application in swine industry. A\&H in SW can be released into the water environment through the direct discharge of SW, effluent from SW treatment plants, and runoff and leaching from farmland polluted by swine wastes. The presence of $\mathrm{A} \& \mathrm{H}$ in the water environment has become an increasing global concern considering their adverse effects to the aquatic organism and human. This review critically discusses: (i) the occurrence of $\mathrm{A} \& \mathrm{H}$ in global water environment and their potential risks to water organisms and human; (ii) the management and technical approaches for reducing the emission of A\&H in SW to the water environment. The development of antibiotic alternatives and the enhanced implementation of vaccination and biosecurity are promising management approaches to cut down the consumption of antibiotics during swine production. Through the comparison of different biological treatment technologies for removing A\&H in SW, membrane-based bioprocesses have relatively higher and more stable removal efficiencies. Whereas, the combined system of bioprocesses and AOPs is expected to be a promising technology for elimination and mineralization of $\mathrm{A} \& \mathrm{H}$ in swine wastewater. Further study on this system is therefore necessary.

Abbreviations: Swine wastewater (SW); Antibiotics and hormones (A\&H); Sulfonamide antibiotics (SMs); Tetracycline antibiotics (TCs); Sulfamethoxazole (SMX); Sulfamethazine (SMZ); Sulfadiazine (SDZ); Tetracycline (TC); Oxytetracycline (OTC); Chlortetracycline (CTC); Doxycycline (DC); Estrone (E1); 17ß-Estradiol (E2); Estriol (E3); 17ß-Estradiol (EE2); Antibiotic resistant bacteria (ARB); Antibiotic resistant genes (ARGs); Endocrine disrupting chemicals (EDCs); Confined animal feeding operations (CAFOs); Extracellular polymeric substances (EPS); Sludge retention time (SRT); Advanced oxidation processes (AOPs) 
Keywords: Swine wastewater, Antibiotics and hormones, Water pollution, Management approach, Technical approach

\section{Introduction}

Antibiotics are widely used in swine industry to treat and prevent the diseases caused by bacterial infections. They can either kill the bacteria or inhibit their growth or reproduction based on their modes of action [1]. Thus, antibiotics are important tools to prevent, control and treat diseases in food animal production [2]. Hormones are essential for the normal development, maturation and physiological functioning of many vital organs and processes in the body [3]. Both antibiotics and hormones have been proved effective for promoting the growth of pigs [4-6]. Since the 1950s, livestock producers use A\&H regularly as the supplements in animal feed and water to increase animal production, and prevent or treat their diseases [6-8]. According to the report by Food and Drug Administration (FDA), 80\% of antibiotics were sold in the United States for livestock production, the amount and route of different classes of antibiotics used in livestock in 2017 was displayed in Fig. 1 [9, 10]. The consumption of antibiotics can increase by $67 \%$ globally and nearly double in Brazil, Russia, India, China, and South Africa, between 2010 and 2030 [11]. In comparison with other livestock, antibiotics are commonly used as the growth promoter in swine farming [12]. Van Boeckel et al. [11] indicated that the global average annual consumption of antimicrobials per kilogram of animal produced was $45 \mathrm{mg} / \mathrm{kg}, 148 \mathrm{mg} / \mathrm{kg}$, and $172 \mathrm{mg} / \mathrm{kg}$ for cattle, chicken, and pigs, respectively. Specifically, tetracycline and sulfonamide antibiotics are the most common antibiotics used in swine production worldwide [13]. 


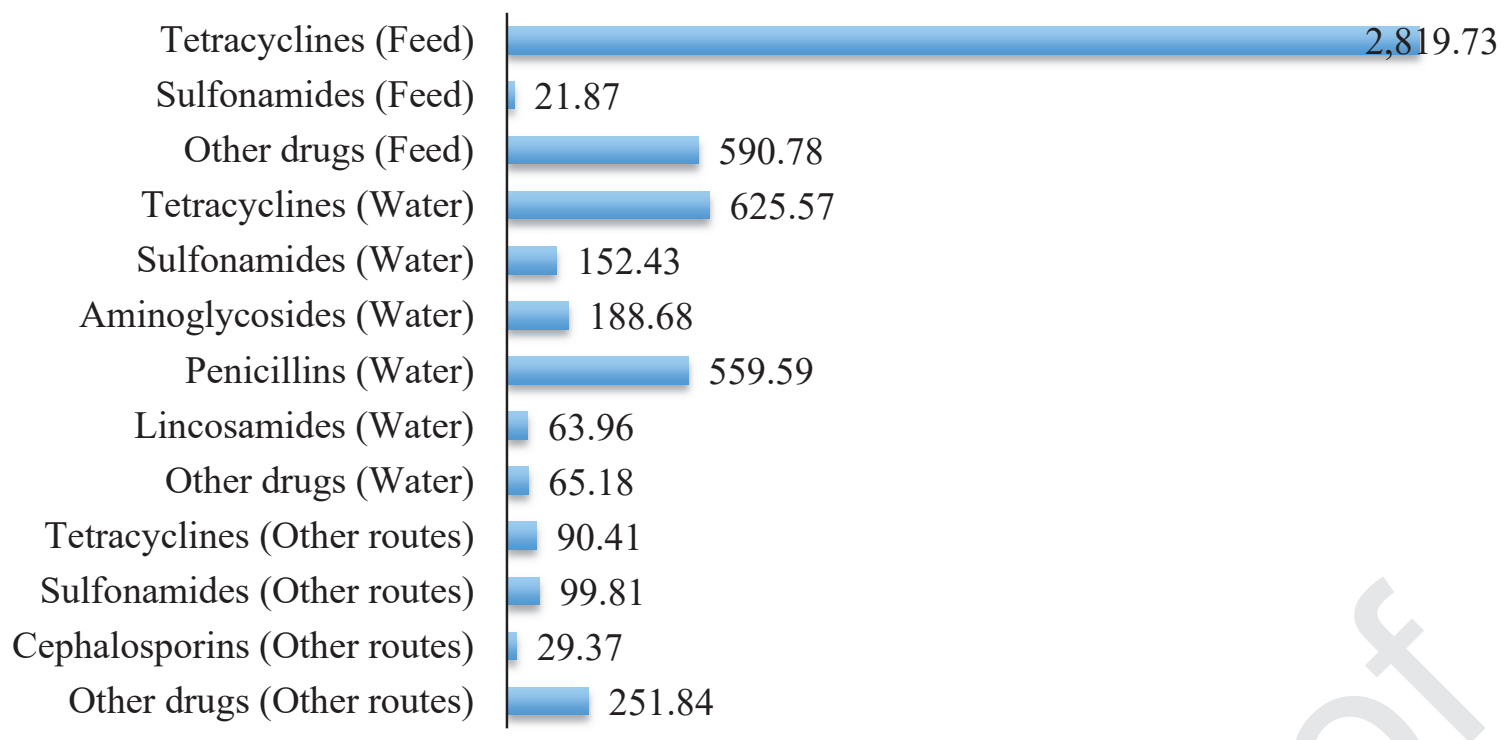

Fig. 1 The amount and route of different classes of antibiotics used in livestock in the United States in 2017, in 1000 kilograms [10].

Pork has been reported as the most widely consumed meat worldwide, with the annual consumption of 110 million tons [14]. Especially in China, $65 \%$ of the meat consumed is pork [15]. The increasing pork demand has prompted the shift of swine production from smaller, family-owned farms to larger, industrialized confined animal feeding operations (CAFOs) [16]. To prevent and treat diseases caused by the high hog population density in CAFOs, increasing amount of antibiotics are routinely used in swine industries [17]. As predicted by Liu et al. [18], the usage of antibiotics in China by 2030 will be more than 30 thousands of tons, which is two times higher than the amount used in 2010. Moreover, the development of concentrated swine feeding operations results in large quantities of SW production. For example, more than 460 million tons of SW was generated in 2011 in China [18].

In fact, $\mathrm{A} \& \mathrm{H}$ are not well absorbed by pigs, about $70-90 \%$ of them can be excreted via urine or feces as intact bioactive substances or metabolites [19]. That is why high concentrations of antibiotics and hormones are detected in SW. Due to their wide usage, tetracycline and sulfonamide antibiotics are the most frequently detected antibiotics in SW, 
with the concentrations up to 685.60 and $324.4 \mu \mathrm{g} / \mathrm{L}$, respectively. Estrogenic hormones,

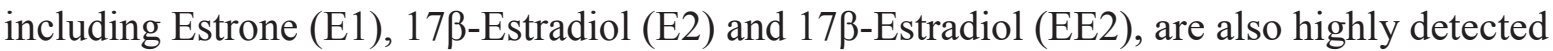
in SW at concentrations ranging from $17.2-4728 \mathrm{ng} / \mathrm{L}, 8-542 \mathrm{ng} / \mathrm{L}$ and $182-357 \mathrm{ng} / \mathrm{L}$, respectively $[19,20]$. A\&H are only partially removed in SW treatment systems because of their persistence and continuous introduction, leading to their continuous emission into the aquatic environment [21]. In addition, swine wastes are commonly applied to farmland as fertilizers or for irrigation in most developing countries and some developed countries, which results in nonpoint source pollution of ground or surface waters [22]. Actually, multiple classes of A\&H have been detected at high levels in surface and groundwater samples collected from the sites close to swine farms $[23,24]$.

The presence of these $\mathrm{A} \& \mathrm{H}$ in water environment can cause serious risk to human health and eco-environmental security, due to their selective pressure on antibiotic resistance and endocrine disrupting effects in the environment [20]. In order to mitigate the potential risks caused by such $\mathrm{A} \& \mathrm{H}$ in the environment, not only strategies have to be implemented to reduce the use of $\mathrm{A} \& \mathrm{H}$ in swine industries, effective technologies are also crucial for removing A\&H from SW before their final release into the environment. Therefore, this review comprehensively discussed the occurrence and risk of A\&H in water environment firstly, and then summarized the control approaches of A\&H in SW, including their management and technical strategies.

\section{Occurrence and risks of $A \& H$ in water environment}

Antibiotics in SW have been highly detected in surface water and groundwater worldwide. Although a wide range of concentrations of antibiotics was detected in the water environment, relatively high levels of antibiotics were detected in the surface water adjacent to the livestock farms. For example, high concentrations of sulfonamide antibiotics (560 $4660 \mathrm{ng} / \mathrm{L})$ and tetracycline antibiotics (810-2420 ng/L) were detected in surface water 
around the livestock farms in Jiangsu Province, China [25]. Up to $68000 \mathrm{ng} / \mathrm{L}$ of oxytetracycline (OTC) were detected in stream water in the vicinity of a livestock farm [26]. Jiang et al. [27] also indicated that the overall contaminations of antibiotics were more serious in suburban sites than those in unban, due to the intensive livestock activities in suburban area along the river. Moreover, the variety of antibiotic concentrations in water environment is consistent with their change in SW, which vary with seasonal changes. Generally, the detectable frequencies and mean concentrations in winter are higher than those in summer [28-30]. Thus, livestock farming wastewater mainly contributes to the high levels of residual antibiotics in the downstream water environment [31]. The review by Fekadu et al. [32] also confirmed that the direct discharge of livestock animal farm wastewater was one of the major reasons for the high concentrations of pharmaceuticals in aquatic environments in the African and European.

The occurrence of antibiotics in the water environment is recognized as an emerging issue due to the potential adverse effects of these compounds posed to the aquatic life and human [20]. Previous reports indicated that antibiotics had toxic effects on the microbial structure, growth, respiration and enzyme activity of aquatic microorganisms, including proteobacteria, cyanobacteria, algae, daphnia and fish [67, 68]. For instance, Park and Choi [69] investigated the acute and chronic toxicity of veterinary antibiotics to microbes, invertebrates, and fish. Through the comparison between the predicted no effect concentrations (PNECs) and the measured environmental concentrations (MECs) of those compounds, the author indicated that SMX, sulfathiazole, CTC, OTC, and amoxicillin showed high potential to affect the aquatic ecosystems. Algae are the basis of the food chain, even slight decreases in the algal population may affect the balance in an aquatic system [70]. Tetracycline and sulfonamide antibiotics have been discovered inhibiting the growth of algae by affecting their chloroplast replication, transcription/ translation and 
metabolic pathways [71-73]. Fish seems less sensitive to antibiotics than algae $[45,74]$. However, considering the bioaccumulation of antibiotics in invertebrate and fish muscles after long-term exposure, there are high risks to human who consume the aquatic organisms with bio-accumulated antibiotics [75]. The toxicity of antibiotics can be affected by their concentrations, exposure time, aquatic species and the co-occurrence of other antibiotics and/or other contaminants [76]. As concluded by previous researches, the antibiotics mixture could arise much stronger toxicological risk to the aquatic organisms than individual compounds $[38,67,77,78]$.

Long-term exposure to low doses of antibiotics in the water environments exerts a selective pressure on autochthonous bacterial communities, which not only poses a threat on aquatic organisms, but also contributes to the development of antibiotic resistant bacteria (ARB) and antibiotic resistant genes (ARGs) $[38,79,80]$. ARB and ARGs are regarded as emerging pollutants, and their presence in the water environment has become an increasing global concern [81]. ARGs encoding resistance to a broad range of antibiotics have been detected in the water environment, especially in the water impacted by swine wastes [8285]. ARGs in surface water and soils (fertilized or irrigated by SW) can leach into groundwater [84, 86]. For example, Sapkota et al. [84] observed that high levels of erythromycin, tetracycline, and clindamycin resistance in Enterococcus spp. recovered from surface water and groundwater situated down gradient of a swine CAFO compared with surface water and groundwater located up gradient of the facility. Tetracycline resistance genes encoding both ribosomal protection proteins and efflux pumps have also been detected in wells near swine lagoons and the groundwater as far as $250 \mathrm{~m}$ downstream from waste lagoons of swine farms [81].

ARGs can transfer among different bacteria through horizontal gene transfer. Eventually, ARGs in the water environment can easily transfer to both human and animal 
pathogens, creating a severe health risk to both human and animals by greatly limiting the antibiotics used to treat the infectious diseases [87]. Such antibiotic resistance is a huge threat to human and animals when common infectious diseases were untreatable. A new antibiotic resistance superbug, Staphylococcus epidermidis - which can resist all known antibiotics has been discovered by Australian scientists in 2018 [88]. As reported by the United State Centre for Disease Control and Prevention (US CDC), about 2 million people infected by antibiotic resistant-bacteria annually, resulting in at least 23000 death per year. In Europe, the death number caused by antibiotic resistance was up to 25,000 each year according to the reports by the European Centre for Disease Prevention and Control (ECDC). If antibioticresistant infections are not tackled, 10 million people could die every year worldwide by 2050 [89]. The research by Hsu et al. [90] concluded that the development of better management strategies for livestock farming would help to decrease antibiotic resistance in the surrounding environment.

In addition to antibiotics, $\mathrm{SW}$ is also a major source of estrogenic hormones pollution to the water environment [91]. Estrogenic hormones have been frequently detected in surface water and groundwater [92]. The evaluation by $\mathrm{Xu}$ et al. [93] found that antibiotics were the most ubiquitously organic contaminants in aquatic environment of China, and more than half of the non-antibiotic pharmaceuticals were hormones. As reviewed by Aris et al. [92], estrogenic hormones in the global water environment ranged from not detected (ND) to 180 ng/L for E1, ND to $134 \mathrm{ng} / \mathrm{L}$ for E2, ND to $94 \mathrm{ng} / \mathrm{L}$ for E3, and ND to $133.64 \mathrm{ng} / \mathrm{L}$ for EE2, respectively. Higher concentrations of hormones are also been detected in the environment influenced by livestock wastes. For instance, the concentrations of E1, E2, and E3 in receiving river discharge from a concentrated livestock feedlot were up to 1267, 313.6, and $210 \mathrm{ng} / \mathrm{L}$, respectively [94]. The surface water in China has been reported containing the maximum concentration of E1, E2 and E3 [92]. This could be explained by the abuse and 
illegal use of hormones as animal-feed additives in China [94, 95]. Hormones also have been highly and frequently detected in the groundwater and drinking water in China [96]. Fan et al. [97] stated that E1 and E2 have been detected in 53 out of 62 drinking water treatment works and 31 out of 62 drinking water treatment works from 31 major cities in China. The maximum detected concentrations were $0.1 \mathrm{ng} / \mathrm{L}$ and $1.7 \mathrm{ng} / \mathrm{L}$ for E1 and E2, respectively.

Hormones can cause significant biological responses even at very low concentrations [98]. Steroidal hormones in SW are also known as endocrine disrupting chemicals (EDCs), which can affect the endocrine system of aquatic species by altering sex determination, delaying sexual maturity, and decreasing secondary sexual characteristics even at low concentrations (ng/L) $[19,92,95]$. Specifically, the occurrence of EDCs in the water environment can result in abnormal reproductive and physiological behaviours of nontargeted aquatic organisms [99]. Prolonged exposure to hormones can cause demasculinization of male fish via lowering testicular testosterone synthesis, reducing testis size, increasing vitellogenin (vtg) concentration $[95,100]$. Hormones including E1, E2 and EE2 have been implicated in the feminization of male fish at concentrations as low as $1 \mathrm{ng} / \mathrm{L}$ $[101,102]$. Meanwhile, the female fish could be defeminised by exposure to hormones through decreasing the ratio of estrogen: androgen [92]. Leet et al. [103] reported that lower fish species richness was detected in the water environment affected by livestock wastes. Fishes in such influenced water exhibit faster somatic growth and lower reproductive condition compared to individuals from the reference site. Orlando et al. [104] investigated the influence of EDCs on feral fish inhabited in streams receiving feedlot effluent; the result demonstrated a reduced reproductive fitness in male fathead minnows. The changes in male fish characteristics strongly affect the fish population and cause an imbalance in the aquatic environment. Even worse, the accumulation of hormones in the environment and the human 
food chain can have serious adverse effects to human health, such as causing the potential cancer diseases and a reduction in the fertility system [95].

\section{Control approaches for A\&H in SW}

The use of antibiotics in food animal industries are applied for four main purposes, as shown in Fig. 2. A\&H were reported as the most effective agents for improving growth and feed efficiency in the entire growing-finishing period of pigs, and reducing mortality and morbidity, particularly in young pigs [105]. The extremely intensive swine operation with high population density results in high disease risk of pigs and rapid dissemination of infectious agents. In this case, increasing amounts of antibiotics in swine husbandry are applied as the therapeutics to treat clinical diseases; as the biosecurity to control the spread of illness in a herd or flock, and as the vaccination to prevent infectious disease by stimulating an individual's immune system [106]. In the meantime, sub-therapeutic dose of antibiotics are added in swine feed and water to improve the daily weight gain and feed efficiency of pigs mainly by alterations in digestion and disease suppression [107]. Antibiotics may also help to make more energy and nutrients available for animals through reduction of total bacterial burden in the gut, and increase nutrient absorption by thinning of the gut mucosal layer [108, 109]. Hormones can contribute to control the extent of growth, muscle and fat production, feed consumption [110]. Therefore, A\&H are effective tools for swine health control and production performance, which facilitate the development of intensive and large-scale farming industry [111]. However, considering the risks of A\&H in SW to the environment and human health, the management and treatment of such additives in swine industries has raised great public concern. 


\section{Antibiotics in animal husbandry}

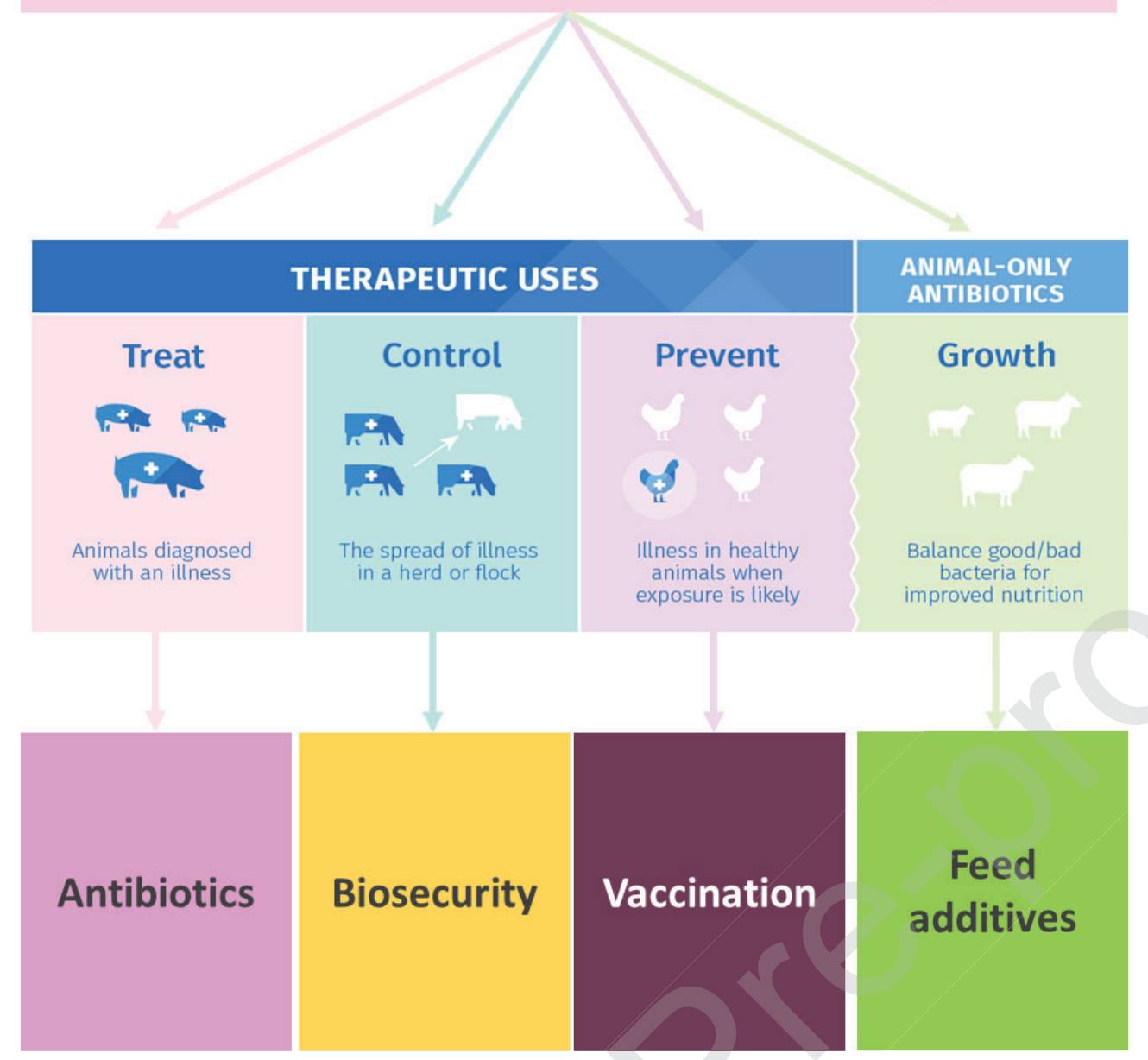

Fig. 2 Potential trends for controlling the use of antibiotics in animal husbandry [112].

\subsection{Management approaches}

To mitigate the environmental and health risk of A\&H, many countries have already taken action to reduce the use of $\mathrm{A} \& \mathrm{H}$ in food-producing animals [113]. For example, in Europe, hormone growth promoters were banned in the 1980s over food safety concerns, the routine use of antibiotics for growth promotion also has banned since 2006 [114]. The U.S. Food and Drug Administration (FDA) placed restrictions on antibiotic use in animals in 2016, antibiotics can only be used in food animals to assure animal health [9]. The Australian Government has released its first National Antimicrobial Resistance Strategy (AMR) 20152019 to guide Australia's response to the threat of antibiotic misuse and resistance [115]. World Health Organization (WHO) strongly recommends an overall reduction in the use of 
all classes of medically important antibiotics in food-producing animals, including complete restriction of these antibiotics for growth promotion and disease prevention without diagnosis [116]. However, antibiotics are still in use for growth promotion of food animals in several large livestock producing and exporting countries, such as China and Brazil [117].

It should be noted that a complete ban on antimicrobial-use in swine production is likely at the cost of lower production and poorer swine health outcomes. Following the withdrawal of antibiotics from feeds in Denmark during the late 1990s, many pig herds suffered from enteric infections and diarrhoea among weaner pigs, leading to the reduction of pig production and the increase of farming costs (at least from 1 to 3 US dollars per pig) [118, 119]. Therefore, the challenge for swine farmers is to reduce antibiotics while keeping high performance. To meet such aims, management approaches should focus on discovering antibiotic alternatives to substitute the role of antibiotics in relation to growth promotion and disease prevention. Meanwhile, the development of vaccination and the application of biosecurity are also essential for diseases prevention and control.

\subsubsection{Replace growth-promoting antibiotics with feed additives}

In recent years, extensive research has been focusing on the development of antibiotic alternatives to ensure the swine health and production $[107,108,120,121]$. The antibiotic alternatives are expected to: 1) enhance the immune response of pigs, 2) reduce the pathogen load in their gut, 3) stimulate the establishment of beneficial gut microbes, and 4) stimulate the digestive function of pigs [120]. Based on previous review reports, the most promising alternatives are essential oil, enzymes, organic acids, prebiotics, probiotics and clays. The characteristics and functions of these antibiotic alternatives are listed below, see Table 1. Table 1

Characteristics and major functions of selected antibiotic alternatives ${ }^{\mathrm{a}}$

\begin{tabular}{ll}
\hline Promising & Characteristics \\
alternatives &
\end{tabular}




$\begin{array}{ll} & \text { Essential oils have } \\ & \text { antimicrobial, anti- } \\ \text { Essential oils } \quad \text { inflammatory, } \\ \\ \text { antioxidative, and } \\ \text { coccidiostatic properties }\end{array}$

Organic and inorganic acids

Enzymes

Probiotics
Organic and inorganic acids can be both bacteriostatic and bacteriocidal and these actions depend on the levels of their inclusion

Enzymes can breakdown proteins, fats and carbohydrates by proteases, lipases and several carbohydrases, making them to be better digested and absorbed as energy sources

Probiotics are designed to encourage certain benign strains or species of bacteria in the gut at the expense of less desirable ones
1) Enhancing digestibility and immunity; 2)

Promoting gut health by minimizing the effect of the pathogenic bacteria; and 3) Controlling inflammation, oxidative stress, microbiome, gut chemosensing and bacterial quorum sensing (QS), to generate better production performance of animals odor and ammonia emission.

1) Lowering digesta $\mathrm{pH}$ in the stomach in particular and aiding protein digestion; 2) Reducing microbial competition with the pig for nutrients; 3) Stimulating (pancreatic) enzyme production and activity in the small intestine; 4) Providing nutrients preferred by intestinal tissue to enhance the mucosal integrity and function; and 5) Stimulating secretion of pancreatic enzymes.

1) Improving nutrient utilization, gut health, gastrointestinal health and metabolic profile;

2) Minimizing proliferation of pathogenic bacteria; and 3) Altering the gastrointestinal bacteria ecology of swine.

1) Stimulating the development of a healthy microbiota-predominated by beneficial bacteria; 2) Preventing enteric pathogens from colonization; 3) Increasing digestive capacity and lowering the $\mathrm{pH}$; 4) Improving mucosal immunity; and 5) Enhancing gut tissue maturation and integrity. 


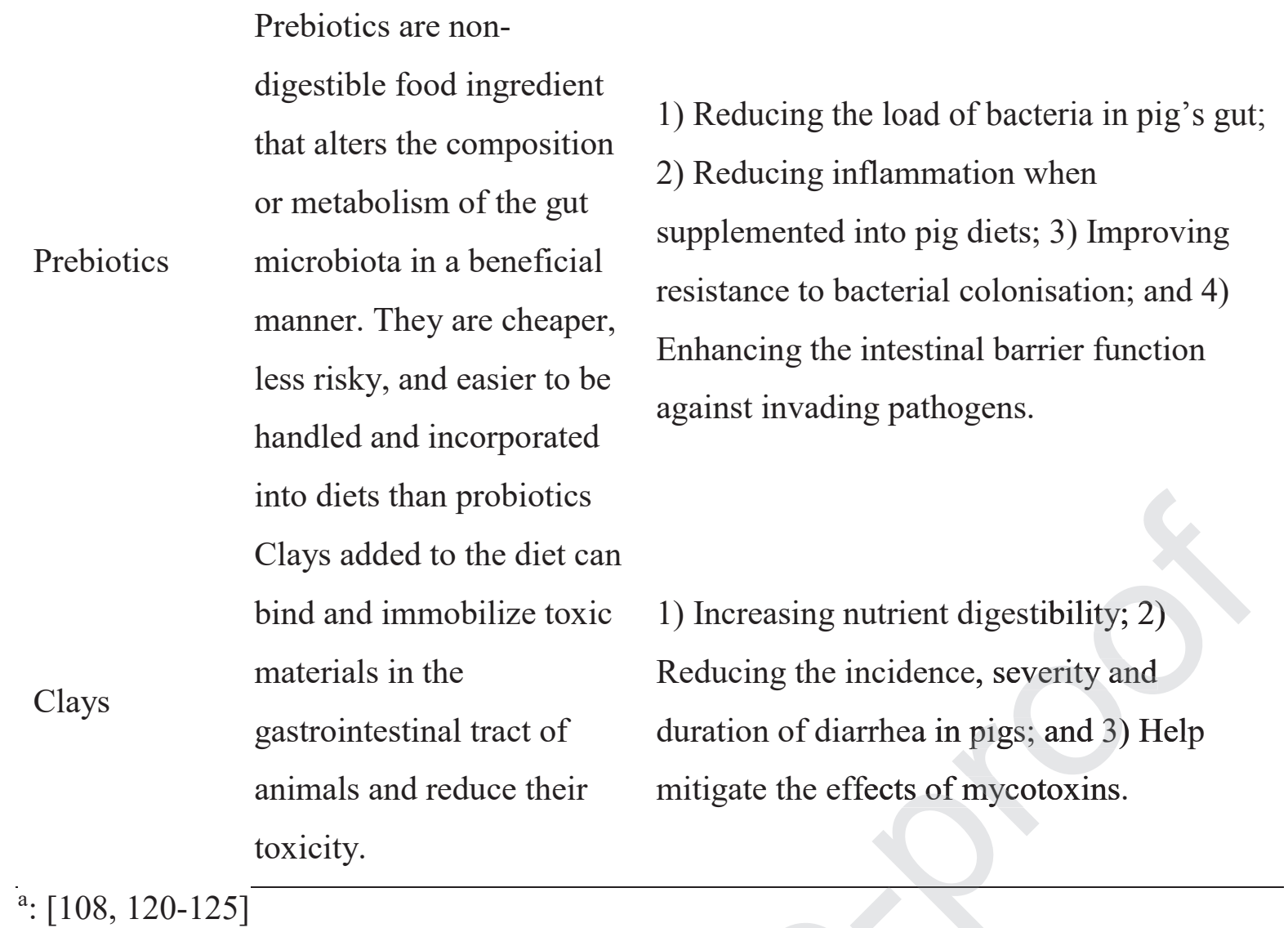

These additives all have great potential as the alternatives of antibiotics for swine growth performance and enhancement. It is difficult to recommend a special one due to their variable outcomes under different conditions [107]. Several previous studies believed that a combination of different alternatives had better effects on the production and health of pigs, compared with that of individual compounds [108, 126, 127]. The main reason might be that the combined additives cover the shortage of the individuals, and their synergistic effect enhances efficiency to combat pathogens $[108,128]$. However, the modes of action of these alternatives, their effects on pig growth and economic efficiencies are still unclear which requires further study.

\subsubsection{Implement vaccination and biosecurity in diseases prevention and control.}

Vaccines and vaccination can provide cost-effective and long-term protection against disease by stimulating the natural defence system of the host to generate sufficient immunity. Previous studies have proved that vaccines can be used to prevent and control the infection 
disease in animal production [129]. Their use can lead to great reductions in antibiotic consumption and mitigate the adverse effects of antibiotics to the environment. To be widely used in food producing animals, vaccines have to be safe, effective against a broad range of pathogens, easy to use, and cost-effective [130]. Therefore, the development of vaccination technologies and their application in swine industries for disease prevention and control are significant.

In addition, limiting the spread of infectious disease and minimising the level of disease within the herd can also dramatically reduce the use of antibiotics, vaccines and other chemicals. The application of high standards of biosecurity, including internal and external biosecurity, is crucial to maintain swine health $[131,132]$. Internal biosecurity is to prevent the spread of pathogens within a herd $[132,133]$. The factors related to internal biosecurity mainly focus on the pig farming density, disease management, cleaning, disinfection, and management of pigs in the farrowing, nursery and fattening units [134]. External biosecurity relates to the prevention of pathogens entering a herd through purchase and transport of pigs, supply of feed, water and equipment, entry of visitors, and sanitary period between batches [134]. Laanen et al. [131] investigated the relationship between the implementation of biosecurity in pig herds and the pig production as well as the use of antimicrobials, and concluded that both external and internal biosecurity were positively associated with daily weight gain of pigs. The overall and internal biosecurity scores were negatively associated (P $=0.05$ for both, respectively) with the incidence of disease treatment, indicating improved biosecurity might help to reduce the use of antibiotics in pig farms. Fig. 3 summarizes the SWOT analysis for the replacement of growth-promoting antibiotics with feed additives and the implement of vaccination and biosecurity in diseases prevention and control. 


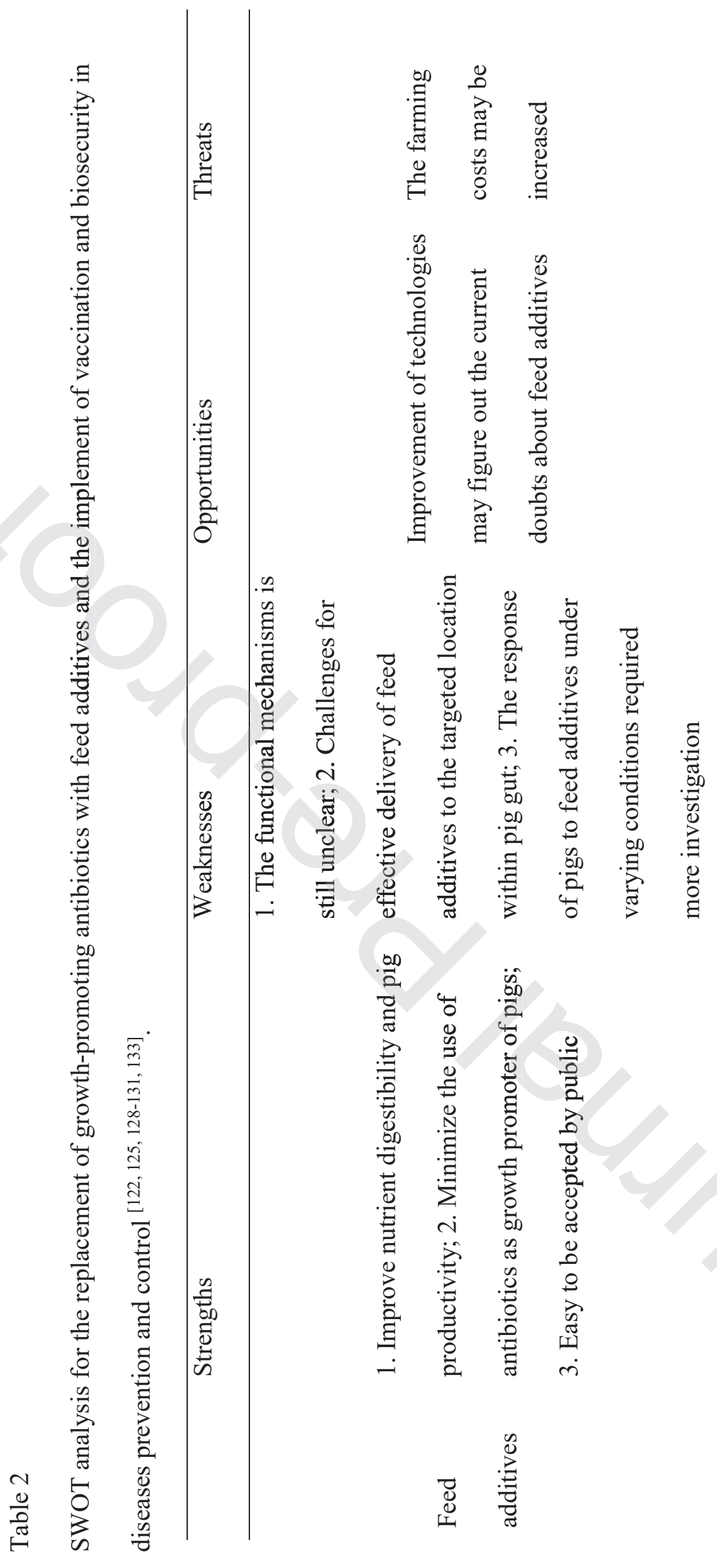



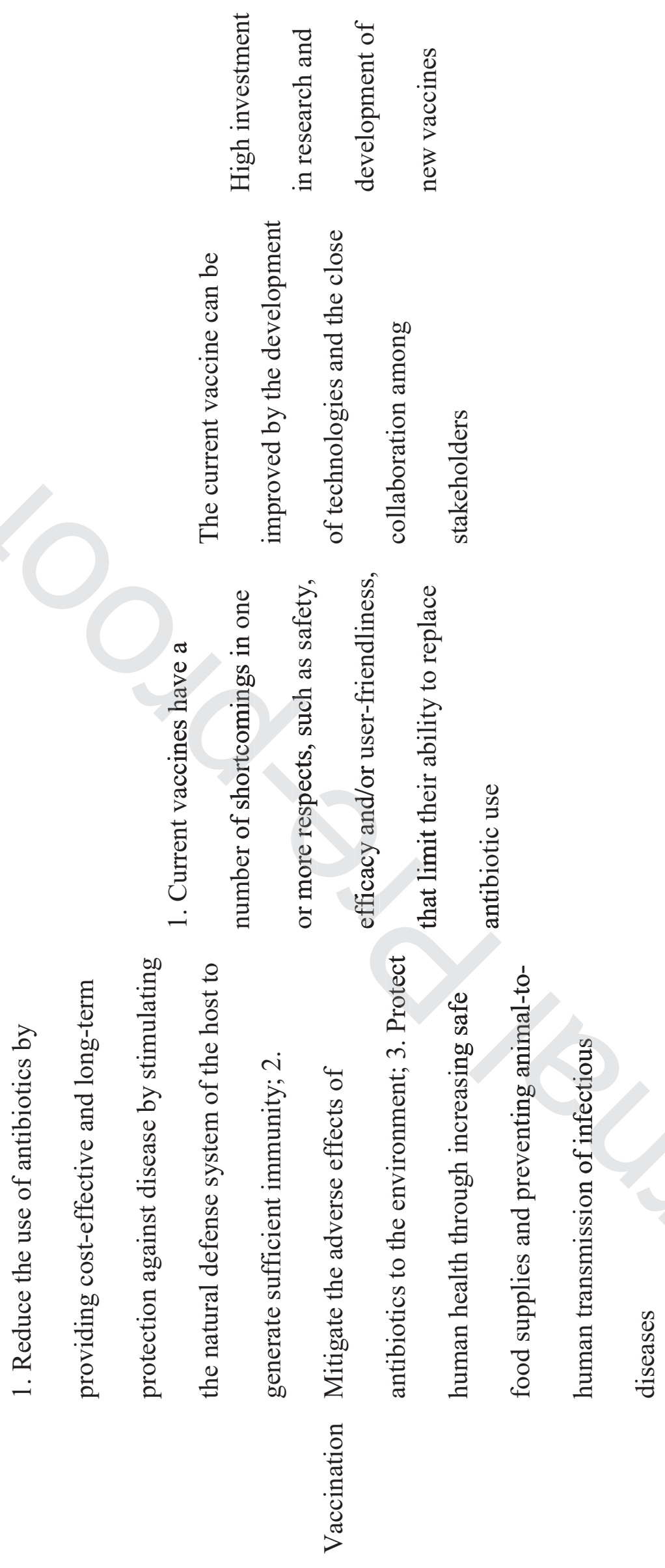


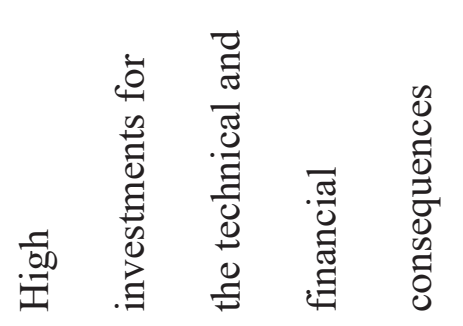

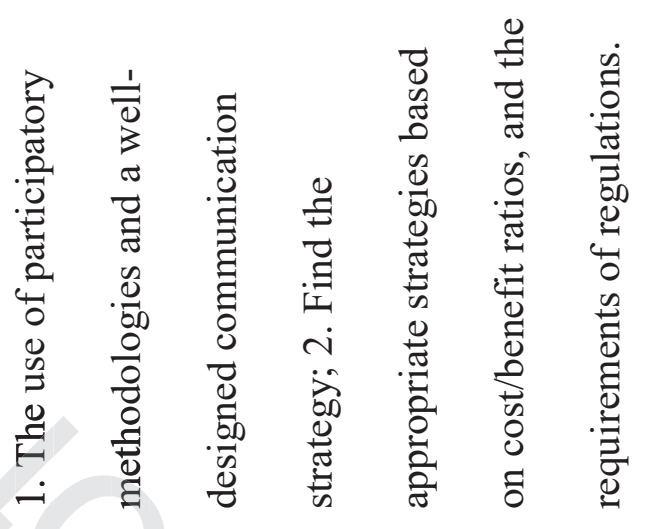

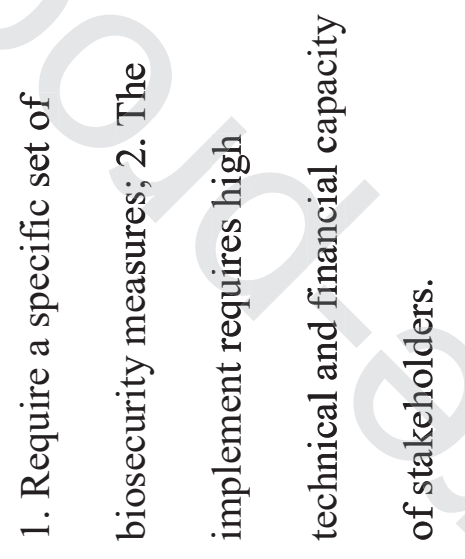

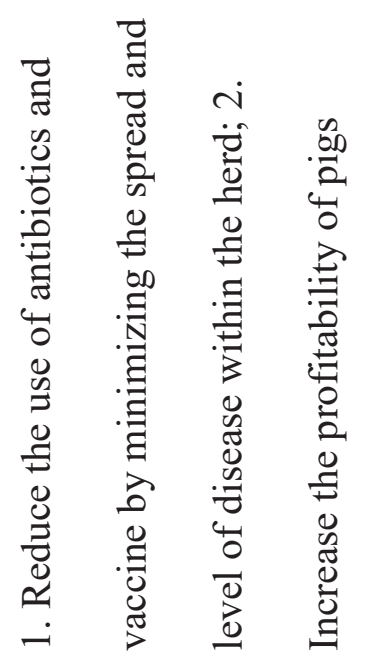

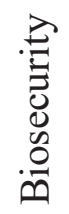


Moreover, improving training to swine farmers is also important, considering their overuse and illegal use of antibiotics in pigs. The farmers should know the regulations and guidelines of the use of antibiotics, the additive dose and the withdrawal time provided by the manufacturer or indicated by the veterinarian, for instance, antibiotics should only be employed to treat bacterial infections [13]. Furthermore, antibiotics used in animals should be the "least important" ones to human health listed by WHO, not those "highest priority critically important" ones. Therefore, enhanced biosecurity, vaccination programs and better management practices are necessary for swine disease prevention and control, and reducing their reliance on antibiotics.

\subsection{Technique approaches}

\subsubsection{Bioprocesses}

In addition to the management approaches, technologies toward eliminating A\&H from SW are equally important to mitigate the adverse effect of those toxicants to the aquatic environment. Biological treatment is the most common technology for livestock wastewater treatment due to their proven robustness, high cost-effectiveness and low environmental impact [19]. Extensive research has focused on the removal of those toxicants from SW by various biological technologies [19, 135-137].

Removal mechanisms, including biodegradation, biosorption, photo-degradation and volatilization, are responsible for removing trace organic pollutants [19]. Biosorption and biodegradation are believed to be the main mechanism for removing A\&H from SW by biological processes [138]. The removal via volatilization mechanism is negligible considering the low Henry's law constant $\left(\mathrm{k}_{\mathrm{H}}\right)\left(<10^{-6} \mathrm{~mol} /\left(\mathrm{m}^{3} \cdot \mathrm{Pa}\right)\right.$ of target A\&H (Table 3) $[139,140]$. Removal by photo-degradation can also be ignored because of the high suspended solid concentration in SW, which blocks the penetration of sunlight in the top layer [19]. 
Table 3

Key physical-chemical properties of target antibiotics and hormones

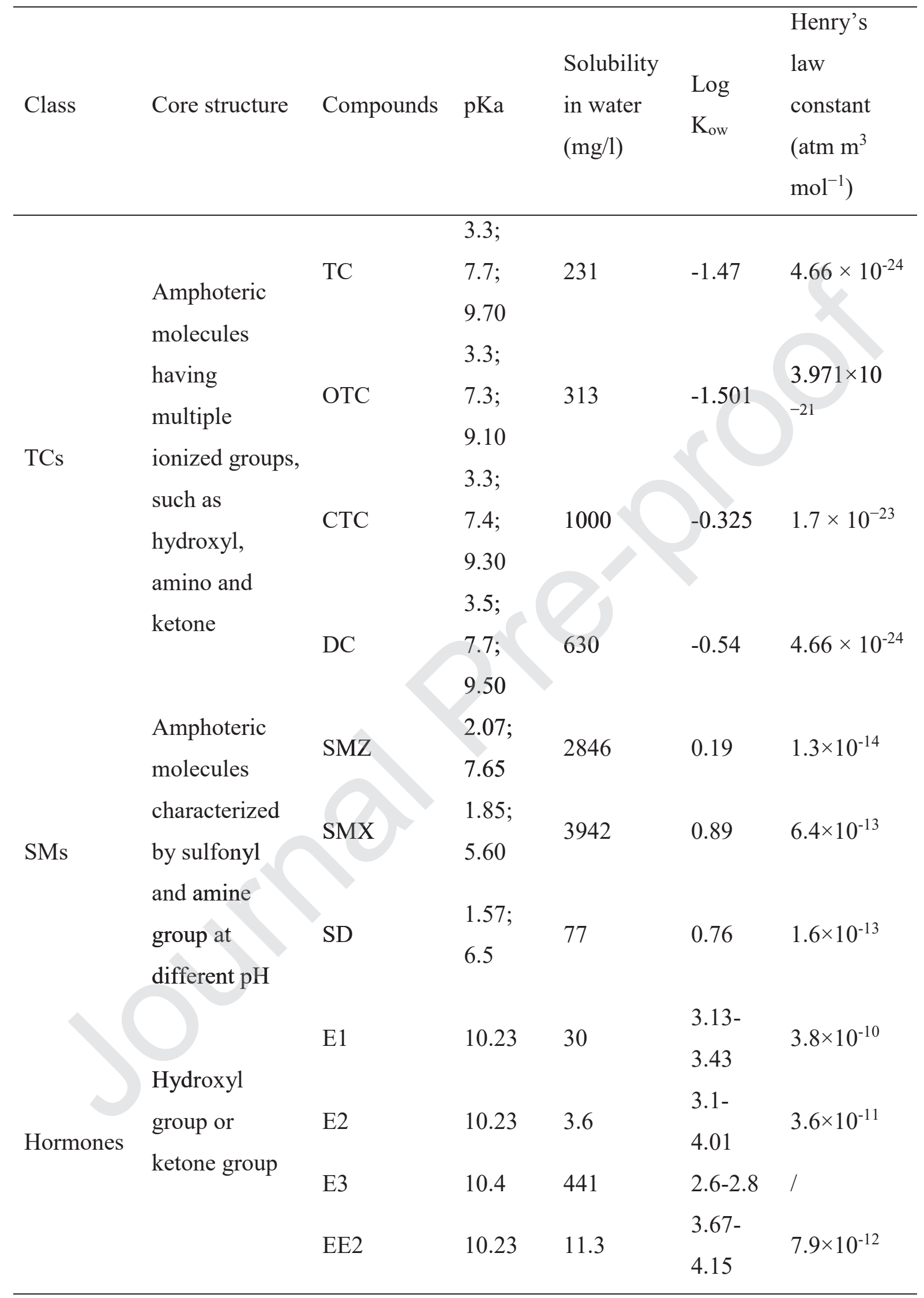


Biosorption is a physico-chemical and metabolically-independent process that happens between organic/inorganic pollutants and biosorbents [141]. Biosorption mechanisms mainly include absorption, adsorption, ion exchange, surface complexation and precipitation [142]. Therefore, the biosorption removal of A\&H from wastewater highly depends on their physical-chemical properties, such as charge, solubility, hydrophobicity and chemical structures. The value of octanol-water partition coefficients (Kow) is usually used by previous studies to characterize the hydrophobicity of compounds and their sorption tendency to the solid phase $[143,144]$. As reviewed by Luo et al. [145], the values of $\log \mathrm{K}_{\mathrm{OW}}<2.5$, between 2.5 and 4 , and $>4$ correspond to the low, medium and high sorption potentials of compounds, respectively. Thereby, the hydrophobic biosorption of tetracycline and sulfonamide antibiotics show lower potential than that of hormones (Table 3). Electrostatic interaction is another mechanism to explain the biosorption of organic compounds onto solid phase [146]. Antibiotic compounds can exist in positive, neutral, and negative forms according to the $\mathrm{pH}$ condition of the solutions and $\mathrm{pKa}$ value of compounds, so the solution $\mathrm{pH}$ is critical for the electrostatic interaction between antibiotics and charged biosorbents [19]. However, the biosorption process can be highly complex due to the different compositions of wastewater and the variety of functional groups in biomass [142]. Tolls [147] indicated that a number of hydrophobicity-independent mechanisms, such as cation exchange, cation bridging, surface complexation, and hydrogen bonding, play significant roles in biosorption removal of antibiotics from wastewater. In addition, microorganisms in biological processes can produce extracellular polymeric substances (EPS) composed of polysaccharide and protein. The EPS can facilitate the biosorption of micropollutants, due to the presence of diverse functional groups, such as carboxyl, amine and hydroxyl groups, and hydrophobic regions [148, 149]. 
Biodegradation is the principal removal mechanism of micropollutants in wastewater. The optimal outcome of biological technologies is to degrade pollutants by microorganism effectively [150]. Mechanisms, including metabolic and co-metabolic pathways by microorganisms, may contribute to the biodegradation removal of A\&H in biological treatment processes $[19,151]$. For example, Müller et al. [152] indicated that activated sludge communities could utilize SMX as carbon and/or nitrogen source for growth, and the biodegradation was enhanced when a readily degradable energy supply (acetate) was provided which fostered metabolic activity. Other previous research also indicated that A\&H in wastewater mainly removed by co-metabolic biodegradation, because their concentrations could be too low to serving as a sole carbon and nitrogen source for the growth of microorganisms [153]. Previous reports about microorganism strains responsible for the degradation of $\mathrm{A} \& \mathrm{H}$ indicated that autotrophic ammonia oxidizers and nitrifying bacteria played a key role in cometabolizing micropollutants, while heterotrophic microbes degraded them via cometabolism and/or metabolism [19, 98, 151, 154].

Different bioprocesses have been investigated for the treatment of A\&H in wastewater and their removal efficiencies are summarized in Table 3. There is a wide range of removal efficiency of A\&H depending on bioreactor types, compound concentrations and different operating conditions. As shown in Table 4, the removal efficiency of sulfonamide antibiotics (SMs), tetracycline antibiotics (TCs) and hormones in conventional aerobic and anaerobic processes was in the range of $0-92.1 \%, 0-100 \%$, and $19 \%-81 \%$, respectively. Comparatively, higher and stable removal efficiencies of these compounds were found in the MBR-based processes, with $67.8 \%$ - 99\% for SMs, $45.7 \%$ - 94\% for TCs and $94.5 \%-99 \%$ for hormones. The CWs system also showed effective removal efficiency of SMs, TCs and hormones, with the value of $40 \%-87 \%, 90 \%-97 \%$ and $31.8 \%-95.2 \%$, respectively. Therefore, the MBR-based processes and CWs systems are more effective for removing 
A\&H from swine wastewater than the conventional activated sludge and anaerobic digestion processes.

Table 4

Removal of A\&H by different bioprocesses[19, 155-159].

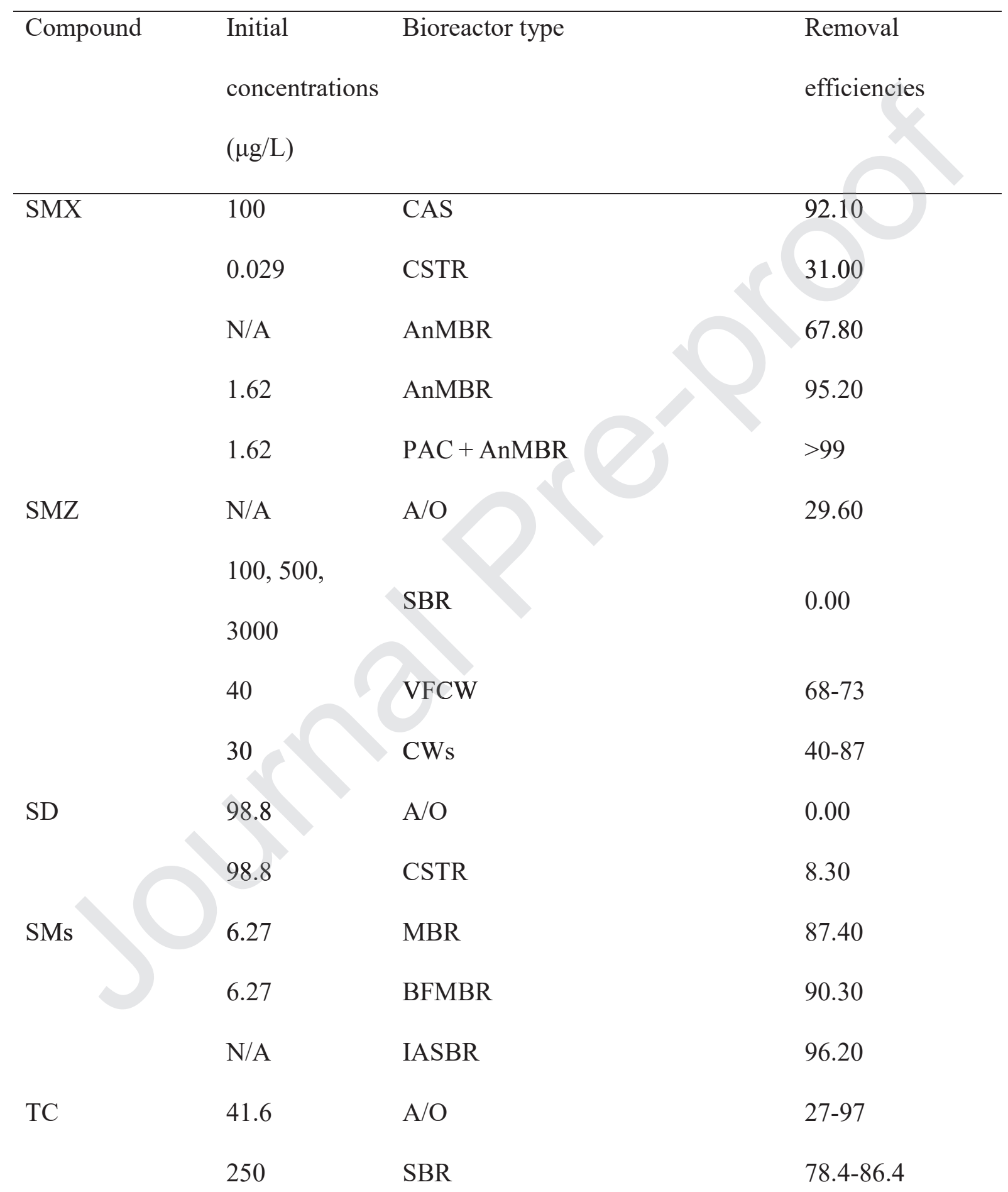




\begin{tabular}{|c|c|c|c|}
\hline & 41.6 & CSTR & 48.90 \\
\hline & 250 & ASBR & $14.97-67.97$ \\
\hline & 100 & VFCW & 94.00 \\
\hline & 30 & CWs & $92-99$ \\
\hline & N/A & MBR & 94.00 \\
\hline & 3.83 & MBR & 80.20 \\
\hline & 2500 & MBR & 89.00 \\
\hline & 3.83 & BFMBR & 81.70 \\
\hline OTC & 23.8 & $\mathrm{~A} / \mathrm{O}$ & $94.1-100$ \\
\hline & 23.8 & CSTR & 96.70 \\
\hline & N/A & MBR & 93.20 \\
\hline & 0.67 & MBR & 85.10 \\
\hline & 0.67 & BFMBR & 88.10 \\
\hline & 40 & VFCW & $91-95$ \\
\hline & 250 & VSSF-CWs & $>90$ \\
\hline & 0.22 & SFCW & 97.00 \\
\hline СТC & 13.7 & $\mathrm{~A} / \mathrm{O}$ & $82.8-90.2$ \\
\hline & N/A & MBR & 78.60 \\
\hline & 0.35 & MBR & 45.70 \\
\hline & 0.35 & BFMBR & 71.40 \\
\hline TCs & 16.21 & MBR & 86.80 \\
\hline & N/A & IASBR & 87.90 \\
\hline & 16.21 & BFMBR & 86.80 \\
\hline Antibiotics & 196 & $\mathrm{BAF}$ & $>82$ \\
\hline E1 & N/A & UASB & 31.00 \\
\hline
\end{tabular}




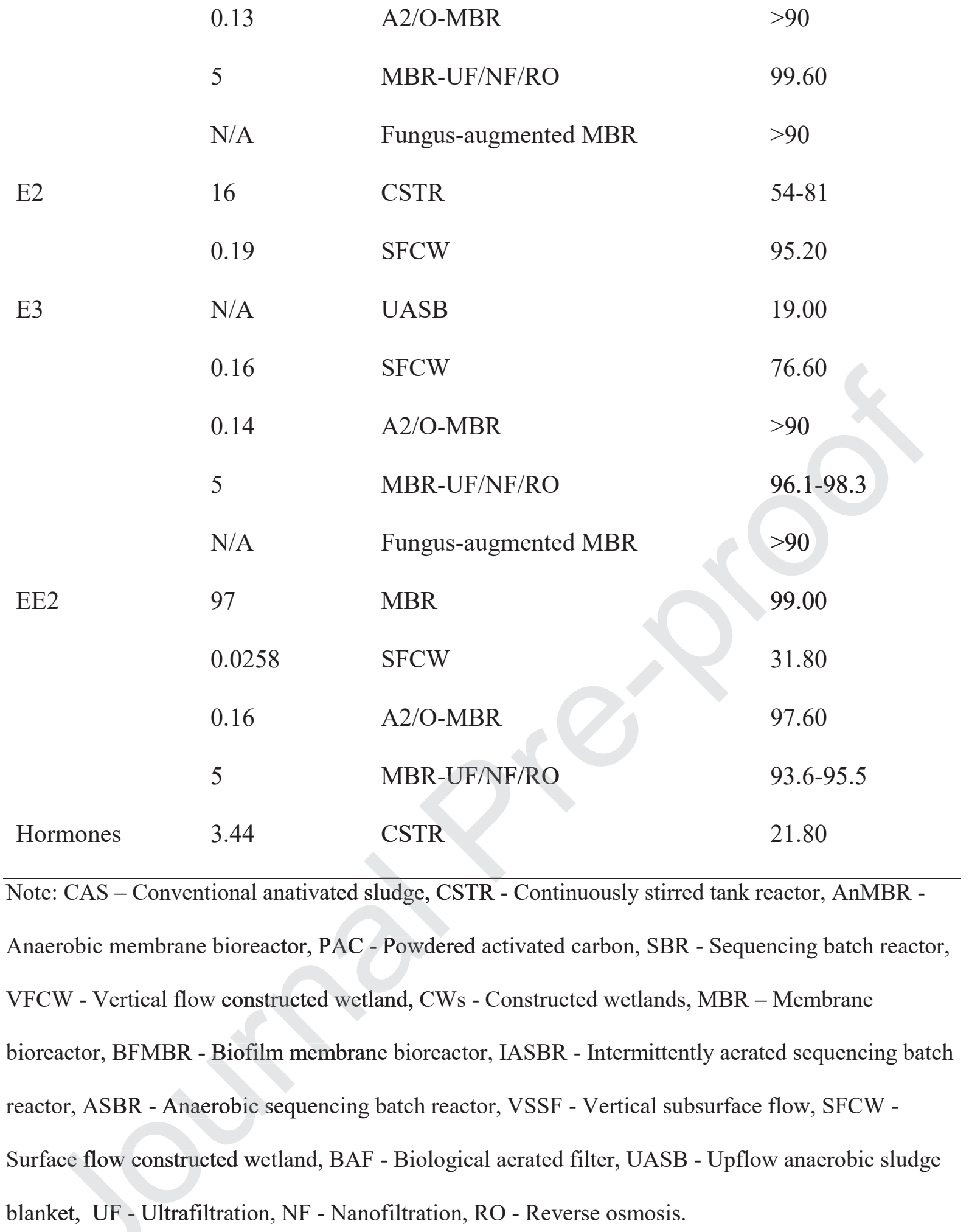

As reviewed by Cheng et al. [19], the biosorption mechanism plays a more important role than biodegradation for removing A\&H in conventional activated sludge (CAS) and anaerobic digestion (AD)processes, resulting in high residues of A\&H in waste sludge of AS 
and $\mathrm{AD}$ processes. Commonly, liquids and solids from SW treatment plants are commonly applied to farmland [19]. Thus, after the treatment by those conventional processes, the aquatic environment still can be affected via the direct discharge of treated SW, and the farmland run-off and leaching. The low biodegradability of A\&H in these conventional bioprocesses is partly attributed to the short sludge retention time (SRT), which limits the growth of antibiotic - biodegrading bacterium [24].

By contrast, high biomass concentration and long SRT can be offered by MBR-based process, which are not only positive to the growth of slow growing microorganisms (nitrification), but also benefit for the increase of biodiversity [160]. Therefore, biodegradation mechanism was reported as the main removal mechanism in advanced MBRbased processes [19]. Furthermore, the high biomass concentration in MBR-based processes makes the process more stable and persistent to the toxic effect of high concentrations of antibiotics. For example, Prado et al. [161] indicated that the toxic effect of TC on microorganisms was less in MBR than that in AS. Hence, the advanced MBR-based processes might be promising technologies for the treatment of $\mathrm{A} \& \mathrm{H}$ in wastewater, such as anaerobic fluidized membrane bioreactor (AFMBR), anaerobic membrane bioreactor (AnMBR) with granular activated carbon (GAC) or powder activated carbon (PAC), or hybrid membrane bioreactors (MBRs). They can achieve effective removal efficiencies (> $90 \%)[19,157,158,162]$. However, membrane fouling in MBR- based processes is a major challenge for their cost-effective application [163]. In addition, the presence of antibiotics in MBR-based processes aggravated the membrane fouling problems [148]. Therefore, more studies on MBR-based processes have to be conducted to reduce the risk of A\&H and control membrane fouling.

Constructed wetlands (CWs) also show a great potential for the treatment of antibiotics and hormones. The removal of $\mathrm{A} \& \mathrm{H}$ in $\mathrm{CWs}$ is the combined action of aquatic plants, 
substrates and microorganisms [164]. Aquatic plants can uptake, transport and metabolize antibiotics through glycosylation and glutathione pathways $[156,165]$. Substrates play an important role in the biosorption removal of A\&H from SW, mainly via hydrophobic partitioning, van der Waals interaction, electrostatic interaction, ion exchange, and surface complexation $[17,164]$. Cheng et al. [19] indicated that the removal contribution of plants and substrates in CWs is highly depended on the concentration and physicochemical property of antibiotics, species of plants and substrates, and the environmental conditions. Different types of CWs, including free water surface constructed wetlands (SF-CWs), horizontal subsurface flow constructed wetlands (HSSF-CWs) and vertical subsurface flow constructed wetlands (VSSF-CWs), have different removal capacities. VSSF-CWs has been regarded as the most efficient type in removing antibiotics and hormones [166]. However, the application of CWs is restricted by their large land requirement and local climate sensitivity [167].

\subsubsection{Advanced oxidation processes (AOPs)}

Except for advanced MBR-based processes, the removal of A\&H in most of conventional biological processes was only partly successful or unsuccessful, suggesting a need of new advanced technologies. Advanced oxidation processes (AOPs), which includes different treatment technologies such as ozonation (O3), UV/H2O2, Fenton (Fe2+/H2O2), photo-Fenton processes (Fe2+/H2O2/UV) and other methods (ultrasonic, radiation), have been considered as promising technologies for effectively or even completely eliminating antibiotics, hormones, herbicides and antiviral compounds from wastewater $[168,169]$. Highly reactive free radicals, especially hydroxyl radicals $(\bullet \mathrm{OH})$ generated via oxidizing agents such as ozone $\left(\mathrm{O}_{3}\right)$ or hydrogen peroxide $\left(\mathrm{H}_{2} \mathrm{O}_{2}\right)$, serve as strong oxidizing tools for 
oxidization of organic compounds into less refractory intermediate species or even mineralization of them into $\mathrm{CO}_{2}$ and $\mathrm{H}_{2} \mathrm{O}[170,171]$.

Anjali and Shanthakumar [169] showed that the removal efficiency of SMs by Solar Photo Fenton, $\mathrm{UV} / \mathrm{H}_{2} \mathrm{O}_{2}, \mathrm{UV} / \mathrm{H}_{2} \mathrm{O}_{2} / \mathrm{Fe}^{2+}$ and Ozonation was $90 \%-97 \%, 97.3 \%-100 \%$, $99.6 \%-100 \%$ and $100 \%$, respectively. By using $\mathrm{UV} / \mathrm{H}_{2} \mathrm{O}_{2}$ and $\mathrm{UV} / \mathrm{H}_{2} \mathrm{O}_{2} / \mathrm{Fe} 2+$ technologies, TCs also achieved high removal efficiencies with the value of $97.2 \%-99 \%$ and $99.4 \%$ 99.5\%, respectively. Ahmed et al. [172] also demonstrated that the removal efficiency of pharmaceuticals by ozonation $/ \mathrm{H}_{2} \mathrm{O}_{2}$, UV photolysis $/ \mathrm{H}_{2} \mathrm{O}_{2}$ and photo-Fenton processes was up to $100 \%$. Hormones can also be effectively removed by ozonation and UV photocatalysis. Thus, in comparison with the conventional biological treatment process, AOPs showed advantages of higher removal efficiency and potentially complete mineralization of A\&H.

However, applying AOPs directly to the removal of A\&H from swine wastewater could consume large amounts of energy (radiation, ozone, etc.) and chemical reagents (catalysts and oxidizers) [173]. Especially for swine wastewater with high concentrations of chemical oxygen demand and nutrients (COD, 3000-15000 mg/L; NH3-N, 400-1400 mg/L; TN, 600$2100 \mathrm{mg} / \mathrm{L}$; TP, 100-250 mg/L), which can compete with the chemical oxidation of the target A\&H $[19,174]$. For example, as reported by Doğruel et al. [175], unnecessary consumption of ozone was caused by the selective preference of ozone for simpler readily biodegradable soluble COD fractions. Qiang et al. [176] indicated that high dose of free chlorine was required to achieve complete removal of antibiotics from swine wastewater due to the rapid competition of ammonia in the wastewater for free chlorine to form monochloramine. The use of such high dose of chlorine could not only increase costs, but also create high concentrations of chlorinated disinfection byproducts with potential toxicity to the environmental and human health. 
One potential alternative to reduce operating costs is the combination of AOPs with biological technologies [171]. The pre-treatment of biological processes can reduce the highly degradable part in swine wastewater, thereby minimizing their competitive oxidation with A\&H [177]. Meanwhile, the recalcitrant contaminants can be degraded by the posttreatment of AOPs. For instance, the research by Ben et al. [174] and Ben et al. [178] concluded the combination of SBR with Fenton's reagent and ozone could achieve effective removal of antibiotics from swine wastewater. The pre-treatment of SBR can remove COD, nutrients and SS from the swine wastewater effectively, thus providing favorable conditions for the following advanced oxidation post-treatment processes.

\section{Future perspectives}

The development and implementation of guidelines for the discharge of A\&Hcontaining wastewater to the environment is necessary to control the uses of A\&H in swine farms and to develop the SW treatment technologies. For this reason, fundamental data about the effect of A\&H on the environment and human health is essential. Similarly, the clear criteria about the reuse of SW and manual in farmland is also required considering the runoff and leaching of $\mathrm{A} \& \mathrm{H}$ from land to the water environment.

It is widely known that the application of antibiotics to swine can control swine disease and promote growth, but their mechanisms of such action is still unclear. To develop effective antibiotic alternatives, the mode of action of antibiotics as swine therapeutic and growth promoter needs to be investigated in future. Although several additives have been suggested to be promising antibiotic alternatives, it is still challenging to evaluate their efficacy, cost-effectiveness, and safety in swine production. Moreover, a deep understanding of the function mechanisms of such alternatives on swine health and growth is also necessary before their application to swine production. Other challenges in reducing the use of 
antibiotics in swine farm are developing effective vaccine to enhance pig's immune system and the application of biosecurity to limit the spread of infectious disease.

The effective removal of A\&H from SW is significant for reducing their adverse effects on the environment. By comparison, MBR-based processes and the integration of biological processes with AOPs are promising technologies for removing A\&H from wastewater. However, only few studies focus on SW so as more work should be done in future. For MBR-based technologies, membrane fouling is the main challenge for full-scale application. The contribution of A\&H to membrane fouling and strategies for fouling control should be the key research direction in future. As for the integrated system of biological processes and AOPs, the most important issue is to optimize the process for the performance of economy and ecology.

\section{Conclusion}

SW is an important source of A\&H pollution considering high levels of these toxicants detected in the adjacent water environment of swine farms. Under long-term exposure, the potential risk caused by the presence of $\mathrm{A} \& \mathrm{H}$ in the water environment cannot be ignored. Thereby, it is strongly necessary to control the use of A\&H in swine industry, though they are important for swine health and production. Feed additives, including essential oil, enzymes, organic acids, prebiotics, probiotics and clays have been reported as promising antibiotic alternatives, but further research is required to explore their modes of action and track their effects on pigs under different conditions. Additionally, the development of vaccination technologies to enhance pig's immune system and application of biosecurity to limit the spread of infectious disease can dramatically reduce the use of antibiotics. Meanwhile, technologies toward eliminating A\&H from SW are equally important to mitigate the adverse effect of such toxicants to the aquatic environment. In biological treatment processes, the removal of A\&H from wastewater by MBR-based technologies and CWs are more efficient 
and stable than that in conventional AS and AD processes. The combined system of bioprocesses and AOPs is expected to be a promising technology for elimination and mineralization of A\&H in swine wastewater. Further research on this system is therefore necessary.

\section{Declaration of interests}

$\bigotimes$ The authors declare that they have no known competing financial interests or personal relationships that could have appeared to influence the work reported in this paper.

$\square$ The authors declare the following financial interests/personal relationships which may be considered as potential competing interests:

\section{Acknowledgement}

This review research was supported by the Centre for Technology in Water and Wastewater (CTWW), University of Technology, Sydney (UTS, FEIT - RIA NGO) and in part by i) the New \& Renewable Energy of the Korea Institute of Energy Technology Evaluation and Planning (KETEP) grant funded by the Korea government Ministry of Knowledge Economy (No. 20183020141270) and ii) the Korean Ministry of Environment as a "Global Top Project" (Project No. 2016002200005). 


\section{References}

[1] J. O. Sekyere, Antibiotic types and handling practices in disease management among pig farms in Ashanti Region, Ghana, J. Vet. Med. (2014), Article ID: 531952.

[2] S. Schwarz, C. Kehrenberg, T. Walsh, Use of antimicrobial agents in veterinary medicine and food animal production, Int. J. Antimicrob. Agents 17 (6) (2001) 431-437.

[3] L. Machlin, Role of growth hormone in improving animal production, Environ. Qual. Saf. Suppl. (5) (1976) 43-55.

[4] H. Gaskins, C. Collier, D. Anderson, Antibiotics as growth promotants: Mode of action, Anim. Biotechnol. 13 (1) (2002) 29-42.

[5] M. G. Ronquillo, J. C. A. Hernandez, Antibiotic and synthetic growth promoters in animal diets: review of impact and analytical methods, Food Control 72 (2017) 255-267.

[6] U. Food, D. Administration, Steroid Hormone Implants Used for Growth in FoodProducing Animals, Retrieved March 24 (2014) 2015.

[7] J. Castanon, History of the use of antibiotic as growth promoters in European poultry feeds, Poult Sci 86 (11) (2007) 2466-2471.

[8] K. Brown, R. R. Uwiera, M. L. Kalmokoff, S. P. Brooks, G. D. Inglis, Antimicrobial growth promoter use in livestock: a requirement to understand their modes of action to develop effective alternatives, Int. J. Antimicrob. Agents 49 (1) (2017) 12-24.

[9] U. S. F. a. D. Administration, FDA policies on antibiotic use in food animals, in, https://www.ejoo.org/-/media/assets/2016/05/fdapoliciesonantibioticuseinfoodanimals.pdf, 2016.

[10] F. D. Administration, 2017 Summary report on antimicrobials sold or distributed for use in food-producing animals, in, Department of Health and Human Services Maryland, 2017. 
[11] T. P. Van Boeckel, C. Brower, M. Gilbert, B. T. Grenfell, S. A. Levin, T. P. Robinson, A. Teillant, R. Laxminarayan, Global trends in antimicrobial use in food animals, Proc. Nati. Acad. Sci. 112 (18) (2015) 5649-5654.

[12] L.-Y. He, G.-G. Ying, Y.-S. Liu, H.-C. Su, J. Chen, S.-S. Liu, J.-L. Zhao, Discharge of swine wastes risks water quality and food safety: Antibiotics and antibiotic resistance genes from swine sources to the receiving environments, Environ. Int. 92 (2016) 210-219.

[13] D. P. Kim, C. Saegerman, C. Douny, T. V. Dinh, B. H. Xuan, B. D. Vu, N. P. Hong, M.L. Scippo, First survey on the use of antibiotics in pig and poultry production in the Red River Delta region of Vietnam, Food and Public Health 3 (5) (2013) 247-256.

[14] Reportlinker, Global Pork Meat Market 2017-2021, in, https://www.prnewswire.com/news-releases/global-pork-meat-market-2017-2021300537453.html, 2017.

[15] M. Song, L.-J. Liu, Z. Wang, T. Nanseki, Consumers' attitudes to food traceability system in China-evidences from the pork market in Beijing, J. Fac. Agric. Kyushu Univ. 53 (2) (2008) 569-574.

[16] K. Radon, A. Schulze, V. Ehrenstein, R. T. van Strien, G. Praml, D. Nowak, Environmental exposure to confined animal feeding operations and respiratory health of neighboring residents, Epidemiology (2007) 300-308.

[17] A. K. Sarmah, M. T. Meyer, A. B. Boxall, A global perspective on the use, sales, exposure pathways, occurrence, fate and effects of veterinary antibiotics (VAs) in the environment, Chemosphere 65 (5) (2006) 725-759.

[18] R. Liu, L. Chen, X. Song, D. Wei, W. Zheng, S. Qiu, Y. Zhao, Treatment of digested piggery wastewater with a membrane bioreactor, Environ. Eng. Manag. J. 15 (10) (2016). 
[19] D. Cheng, H. Ngo, W. Guo, Y. Liu, J. Zhou, S. Chang, D. Nguyen, X. Bui, X. Zhang, Bioprocessing for elimination antibiotics and hormones from swine wastewater, Sci. Total Environ. (2017)

[20] R. Singh, A. P. Singh, S. Kumar, B. S. Giri, K.-H. Kim, Antibiotic Resistance in Major Rivers in the World: A Systematic Review on Occurrence, Emergence, and Management Strategies, J. Clean. Prod. 234 (2019) 1484-1505.

[21] L. Yao, Y. Wang, L. Tong, Y. Deng, Y. Li, Y. Gan, W. Guo, C. Dong, Y. Duan, K. Zhao, Occurrence and risk assessment of antibiotics in surface water and groundwater from different depths of aquifers: A case study at Jianghan Plain, central China, Ecotox. Environ. Safe. 135 (2017) 236-242.

[22] X. Huang, J. Zheng, C. Liu, L. Liu, Y. Liu, H. Fan, Removal of antibiotics and resistance genes from swine wastewater using vertical flow constructed wetlands: Effect of hydraulic flow direction and substrate type, Chem. Eng. J. 308 (2017) 692-699.

[23] L. Tong, P. Li, Y. Wang, K. Zhu, Analysis of veterinary antibiotic residues in swine wastewater and environmental water samples using optimized SPE-LC/MS/MS, Chemosphere 74 (8) (2009) 1090-1097.

[24] W. Ben, Z. Qiang, X. Yin, J. Qu, X. Pan, Adsorption behavior of sulfamethazine in an activated sludge process treating swine wastewater, J. Environ. Sci. 26 (8) (2014) 1623-1629. [25] R. Wei, F. Ge, S. Huang, M. Chen, R. Wang, Occurrence of veterinary antibiotics in animal wastewater and surface water around farms in Jiangsu Province, China, Chemosphere $82(10)(2011) 1408-1414$.

[26] Y. Matsui, T. Ozu, T. Inoue, T. Matsushita, Occurrence of a veterinary antibiotic in streams in a small catchment area with livestock farms, Desalination 226 (1-3) (2008) 215221. 
[27] L. Jiang, X. Hu, D. Yin, H. Zhang, Z. Yu, Occurrence, distribution and seasonal variation of antibiotics in the Huangpu River, Shanghai, China, Chemosphere 82 (6) (2011) $822-828$.

[28] J. Tang, T. Shi, X. Wu, H. Cao, X. Li, R. Hua, F. Tang, Y. Yue, The occurrence and distribution of antibiotics in Lake Chaohu, China: seasonal variation, potential source and risk assessment, Chemosphere 122 (2015) 154-161.

[29] H. Zhang, M. Du, H. Jiang, D. Zhang, L. Lin, H. Ye, X. Zhang, Occurrence, seasonal variation and removal efficiency of antibiotics and their metabolites in wastewater treatment plants, Jiulongjiang River Basin, South China, Environ. Sci.-Proc. Imp. 17 (1) (2015) 225234.

[30] W. Ben, X. Pan, Z. Qiang, Occurrence and partition of antibiotics in the liquid and solid phases of swine wastewater from concentrated animal feeding operations in Shandong Province, China, Environ. Sci.-Proc. Imp.15 (4) (2013) 870-875.

[31] S. Jia, X. He, Y. Bu, P. Shi, Y. Miao, H. Zhou, Z. Shan, X.-X. Zhang, Environmental fate of tetracycline resistance genes originating from swine feedlots in river water, J. Environ. Sci. Health, Part B 49 (8) (2014) 624-631.

[32] S. Fekadu, E. Alemayehu, R. Dewil, B. Van der Bruggen, Pharmaceuticals in freshwater aquatic environments: a comparison of the African and European challenge, Sci. Total Environ. 654 (2018) 324-337.

[33] E. R. Campagnolo, K. R. Johnson, A. Karpati, C. S. Rubin, D. W. Kolpin, M. T. Meyer, J. E. Esteban, R. W. Currier, K. Smith, K. M. Thu, Antimicrobial residues in animal waste and water resources proximal to large-scale swine and poultry feeding operations, Sci. Total Environ. 299 (1-3) (2002) 89-95. 
[34] A. L. Batt, I. B. Bruce, D. S. Aga, Evaluating the vulnerability of surface waters to antibiotic contamination from varying wastewater treatment plant discharges, Environ. Pollut. 142 (2) (2006) 295-302.

[35] W. L. Shelver, H. Hakk, G. L. Larsen, T. M. DeSutter, F. X. Casey, Development of an ultra-high-pressure liquid chromatography-tandem mass spectrometry multi-residue sulfonamide method and its application to water, manure slurry, and soils from swine rearing facilities, J. Chromatogr. 1217 (8) (2010) 1273-1282.

[36] L. Tong, S. Huang, Y. Wang, H. Liu, M. Li, Occurrence of antibiotics in the aquatic environment of Jianghan Plain, central China, Sci. Total Environ. 497 (2014) 180-187. [37] K. Chen, J. Zhou, Occurrence and behavior of antibiotics in water and sediments from the Huangpu River, Shanghai, China, Chemosphere 95 (2014) 604-612.

[38] C. Yan, Y. Yang, J. Zhou, M. Liu, M. Nie, H. Shi, L. Gu, Antibiotics in the surface water of the Yangtze Estuary: occurrence, distribution and risk assessment, Environ. Pollut. 175 (2013) 22-29.

[39] J.-F. Yang, G.-G. Ying, J.-L. Zhao, R. Tao, H.-C. Su, Y.-S. Liu, Spatial and seasonal distribution of selected antibiotics in surface waters of the Pearl Rivers, China, J. Environ. Sci. Health, Part B 46 (3) (2011) 272-280.

[40] M. J. García-Galán, M. S. Díaz-Cruz, D. Barceló, Occurrence of sulfonamide residues along the Ebro river basin: removal in wastewater treatment plants and environmental impact assessment, Environ. Int. 37 (2) (2011) 462-473.

[41] S. Managaki, A. Murata, H. Takada, B. C. Tuyen, N. H. Chiem, Distribution of macrolides, sulfonamides, and trimethoprim in tropical waters: Ubiquitous occurrence of veterinary antibiotics in the Mekong Delta, Environ. Sci. Technol. 41 (23) (2007) 8004-8010. 
[42] F. Tamtam, F. Mercier, B. Le Bot, J. Eurin, Q. T. Dinh, M. Clément, M. Chevreuil, Occurrence and fate of antibiotics in the Seine River in various hydrological conditions, Sci. Total Environ. 393 (1) (2008) 84-95.

[43] D. W. Kolpin, E. T. Furlong, M. T. Meyer, E. M. Thurman, S. D. Zaugg, L. B. Barber, H. T. Buxton, Pharmaceuticals, hormones, and other organic wastewater contaminants in US streams, 1999-2000: A national reconnaissance, Environ. Sci. Technol. 36 (6) (2002) 12021211.

[44] A. Watkinson, E. Murby, D. Kolpin, S. Costanzo, The occurrence of antibiotics in an urban watershed: from wastewater to drinking water, Sci. Total Environ. 407 (8) (2009) $2711-2723$.

[45] W. Li, Y. Shi, L. Gao, J. Liu, Y. Cai, Occurrence of antibiotics in water, sediments, aquatic plants, and animals from Baiyangdian Lake in North China, Chemosphere 89 (11) (2012) 1307-1315.

[46] D. Cheng, X. Liu, L. Wang, W. Gong, G. Liu, W. Fu, M. Cheng, Seasonal variation and sediment-water exchange of antibiotics in a shallower large lake in North China, Sci. Total Environ. 476 (2014) 266-275.

[47] H. Ding, Y. Wu, W. Zhang, J. Zhong, Q. Lou, P. Yang, Y. Fang, Occurrence, distribution, and risk assessment of antibiotics in the surface water of Poyang Lake, the largest freshwater lake in China, Chemosphere 184 (2017) 137-147.

[48] J. Xu, Y. Zhang, C. Zhou, C. Guo, D. Wang, P. Du, Y. Luo, J. Wan, W. Meng, Distribution, sources and composition of antibiotics in sediment, overlying water and pore water from Taihu Lake, China, Sci. Total Environ. 497 (2014) 267-273.

[49] X. Lei, J. Lu, Z. Liu, Y. Tong, S. Li, Concentration and distribution of antibiotics in water-sediment system of Bosten Lake, Xinjiang, Environ. Sci. Pollu. Res. 22 (3) (2015) $1670-1678$. 
[50] J. Tang, F. Zhang, C. Wang, T. Shi, X. Li, R. Hua, Investigation of sulfonamide antibiotics residue in the water of Chaohu Lake and its inlet rivers, J. Safe. Environ. 14 (4) (2014) 334-338.

[51] C. Wu, A. L. Spongberg, J. D. Witter, Use of solid phase extraction and liquid chromatography-tandem mass spectrometry for simultaneous determination of various pharmaceuticals in surface water, Int. J. Environ. An. Ch. 88 (14) (2008) 1033-1048.

[52] A. Boxall, L. Fogg, D. Baird, C. Lewis, T. Telfer, D. Kolpin, A. Gravell, E. Pemberton, T. Boucard, Targeted monitoring study for veterinary medicines in the environment, Environment Agency, Bristol (2006)

[53] W. Deng, N. Li, H. Zheng, H. Lin, Occurrence and risk assessment of antibiotics in river water in Hong Kong, Ecotoxicol. Environ. Saf. 125 (2016) 121-127.

[54] W. Xu, G. Zhang, S. Zou, Z. Ling, G. Wang, W. Yan, A preliminary investigation on the occurrence and distribution of antibiotics in the Yellow River and its tributaries, China, Water Environ. Res. 81 (3) (2009) 248-254.

[55] A. Mendoza, J. Aceña, S. Pérez, M. L. de Alda, D. Barceló, A. Gil, Y. Valcárcel, Pharmaceuticals and iodinated contrast media in a hospital wastewater: a case study to analyse their presence and characterise their environmental risk and hazard, Environ. Res. 140 (2015) 225-241.

[56] M. R. Boleda, M. T. Galceran, F. Ventura, Validation and uncertainty estimation of a multiresidue method for pharmaceuticals in surface and treated waters by liquid chromatography-tandem mass spectrometry, J. Chromatogr. 1286 (2013) 146-158.

[57] W. Li, L. Gao, Y. Shi, J. Liu, Y. Cai, Occurrence, distribution and risks of antibiotics in urban surface water in Beijing, China, Environmental Science: Processes \& Impacts 17 (9) (2015) 1611-1619. 
[58] K. Stoob, H. P. Singer, S. R. Mueller, R. P. Schwarzenbach, C. H. Stamm, Dissipation and transport of veterinary sulfonamide antibiotics after manure application to grassland in a small catchment, Environ. Sci. Technol. 41 (21) (2007) 7349-7355.

[59] K. K. Barnes, D. W. Kolpin, E. T. Furlong, S. D. Zaugg, M. T. Meyer, L. B. Barber, A national reconnaissance of pharmaceuticals and other organic wastewater contaminants in the United States-I) Groundwater, Sci. Total Environ. 402 (2-3) (2008) 192-200.

[60] Y. Cabeza, L. Candela, D. Ronen, G. Teijon, Monitoring the occurrence of emerging contaminants in treated wastewater and groundwater between 2008 and 2010. The Baix Llobregat (Barcelona, Spain), J. Hazard. Mater. 239 (2012) 32-39.

[61] R. López-Serna, A. Jurado, E. Vázquez-Suñé, J. Carrera, M. Petrović, D. Barceló, Occurrence of 95 pharmaceuticals and transformation products in urban groundwaters underlying the metropolis of Barcelona, Spain, Environ. Pollut. 174 (2013) 305-315.

[62] X. Peng, W. Ou, C. Wang, Z. Wang, Q. Huang, J. Jin, J. Tan, Occurrence and ecological potential of pharmaceuticals and personal care products in groundwater and reservoirs in the vicinity of municipal landfills in China, Sci. Total Environ. 490 (2014) 889-898.

[63] L. A. Schaider, R. A. Rudel, J. M. Ackerman, S. C. Dunagan, J. G. Brody, Pharmaceuticals, perfluorosurfactants, and other organic wastewater compounds in public drinking water wells in a shallow sand and gravel aquifer, Sci. Total Environ. 468 (2014) 384-393.

[64] M. S. Fram, K. Belitz, Occurrence and concentrations of pharmaceutical compounds in groundwater used for public drinking-water supply in California, Sci. Total Environ. 409 (18) (2011) 3409-3417.

[65] M. J. García-Galán, T. Garrido, J. Fraile, A. Ginebreda, M. S. Díaz-Cruz, D. Barceló, Simultaneous occurrence of nitrates and sulfonamide antibiotics in two ground water bodies of Catalonia (Spain), J. Hydrol. 383 (1-2) (2010) 93-101. 
[66] Y. Ma, M. Li, M. Wu, Z. Li, X. Liu, Occurrences and regional distributions of 20 antibiotics in water bodies during groundwater recharge, Sci. Total Environ. 518 (2015) 498506.

[67] P. Välitalo, A. Kruglova, A. Mikola, R. Vahala, Toxicological impacts of antibiotics on aquatic micro-organisms: a mini-review, Int. J. Hyg. Environ. Health 220 (3) (2017) 558-569. [68] K. K. Brandt, A. Amézquita, T. Backhaus, A. Boxall, A. Coors, T. Heberer, J. R. Lawrence, J. Lazorchak, J. Schönfeld, J. R. Snape, Ecotoxicological assessment of antibiotics: a call for improved consideration of microorganisms, Environ. Int. 85 (2015) 189205.

[69] S. Park, K. Choi, Hazard assessment of commonly used agricultural antibiotics on aquatic ecosystems, Ecotoxicology 17 (6) (2008) 526-538.

[70] P. Lanzky, B. Halting-Sørensen, The toxic effect of the antibiotic metronidazole on aquatic organisms, Chemosphere 35 (11) (1997) 2553-2561.

[71] R. A. Brain, M. L. Hanson, K. R. Solomon, B. W. Brooks, Aquatic plants exposed to pharmaceuticals: effects and risks, in: Rev Environ Contam Toxicol, Springer, 2008, pp. 67115.

[72] R. A. Brain, D. J. Johnson, S. M. Richards, H. Sanderson, P. K. Sibley, K. R. Solomon, Effects of 25 pharmaceutical compounds to Lemna gibba using a seven-day static-renewal test, Environ. Toxicol. Chem. 23 (2) (2004) 371-382.

[73] W. Baran, E. Adamek, J. Ziemiańska, A. Sobczak, Effects of the presence of sulfonamides in the environment and their influence on human health, J. Hazard. Mater. 196 (2011) 1-15.

[74] K. Kümmerer, Antibiotics in the aquatic environment-a review-part I, Chemosphere 75 (4) (2009) 417-434. 
[75] Y. Peng, Y. Zhang, H. Huang, C. Zhong, Flexibility induced high-performance MOFbased adsorbent for nitroimidazole antibiotics capture, Chem. Eng. J. 333 (2018) 678-685. [76] P. Grenni, V. Ancona, A. B. Caracciolo, Ecological effects of antibiotics on natural ecosystems: A review, Microchem. J. 136 (2018) 25-39.

[77] A. Magdaleno, M. Saenz, A. Juárez, J. Moretton, Effects of six antibiotics and their binary mixtures on growth of Pseudokirchneriella subcapitata, Ecotoxicol. Environ. Saf. 113 (2015) 72-78.

[78] J. Du, H. Zhao, S. Liu, H. Xie, Y. Wang, J. Chen, Antibiotics in the coastal water of the South Yellow Sea in China: Occurrence, distribution and ecological risks, Sci. Total Environ. 595 (2017) 521-527.

[79] J. L. Martínez, Antibiotics and antibiotic resistance genes in natural environments, Sci $321(5887)$ (2008) 365-367.

[80] M. Huang, F. Qi, J. Wang, Q. Xu, L. Lin, Changes of bacterial diversity and tetracycline resistance in sludge from AAO systems upon exposure to tetracycline pressure, J. Hazard. Mater. 298 (2015) 303-309.

[81] X.-X. Zhang, T. Zhang, H. H. Fang, Antibiotic resistance genes in water environment, Appl. Microbiol. Biotechnol. 82 (3) (2009) 397-414.

[82] A. Anthony A, F. Adekunle C, S. Thor A, Residual antibiotics, antibiotic resistant superbugs and antibiotic resistance genes in surface water catchments: Public health impact, PCE 105 (2018) 177-183.

[83] R. Tao, G.-G. Ying, H.-C. Su, H.-W. Zhou, J. P. Sidhu, Detection of antibiotic resistance and tetracycline resistance genes in Enterobacteriaceae isolated from the Pearl rivers in South China, Environ. Pollut. 158 (6) (2010) 2101-2109. 
[84] A. R. Sapkota, F. C. Curriero, K. E. Gibson, K. J. Schwab, Antibiotic-resistant enterococci and fecal indicators in surface water and groundwater impacted by a concentrated swine feeding operation, Environ. Health Perspect. 115 (7) (2007) 1040.

[85] B. Chen, X. Liang, X. Nie, X. Huang, S. Zou, X. Li, The role of class I integrons in the dissemination of sulfonamide resistance genes in the Pearl River and Pearl River Estuary, South China, J. Hazard. Mater. 282 (2015) 61-67.

[86] H. Heuer, H. Schmitt, K. Smalla, Antibiotic resistance gene spread due to manure application on agricultural fields, Curr. Opin. Microbiol. 14 (3) (2011) 236-243.

[87] Z. Ma, H. Wu, K. Zhang, X. Xu, C. Wang, W. Zhu, W. Wu, Long-term low dissolved oxygen accelerates the removal of antibiotics and antibiotic resistance genes in swine wastewater treatment, Chem. Eng. J. 334 (2018) 630-637.

[88] J. Y. Lee, I. R. Monk, A. G. da Silva, T. Seemann, K. Y. Chua, A. Kearns, R. Hill, N. Woodford, M. D. Bartels, B. Strommenger, Global spread of three multidrug-resistant lineages of Staphylococcus epidermidis, Nature Microbiology 3 (10) (2018) 1175. [89] J. O’Neill, Antimicrobial resistance: tackling a crisis for the health and wealth of nations, Rev. Antimicrob. Resist 20 (2014) 1-16.

[90] J.-T. Hsu, C.-Y. Chen, C.-W. Young, W.-L. Chao, M.-H. Li, Y.-H. Liu, C.-M. Lin, C. Ying, Prevalence of sulfonamide-resistant bacteria, resistance genes and integron-associated horizontal gene transfer in natural water bodies and soils adjacent to a swine feedlot in northern Taiwan, J. Hazard. Mater. 277 (2014) 34-43.

[91] X. Yuan, T. Li, L. Zhou, X. Zhao, Characteristics and risk assessment of estrogenic compounds in rivers of southern Jiangsu province, China, IERI Procedia 9 (2014) 176-184. [92] A. Z. Aris, A. S. Shamsuddin, S. M. Praveena, Occurrence of $17 \alpha$-ethynylestradiol (EE2) in the environment and effect on exposed biota: a review, Environ. Int. 69 (2014) 104119. 
[93] M. Xu, H. Huang, N. Li, F. Li, D. Wang, Q. Luo, Occurrence and ecological risk of pharmaceuticals and personal care products (PPCPs) and pesticides in typical surface watersheds, China, Ecotoxicol. Environ. Saf. 175 (2019) 289-298.

[94] T.-S. Chen, T.-C. Chen, K.-J. C. Yeh, H.-R. Chao, E.-T. Liaw, C.-Y. Hsieh, K.-C. Chen, L.-T. Hsieh, Y.-L. Yeh, High estrogen concentrations in receiving river discharge from a concentrated livestock feedlot, Sci. Total Environ. 408 (16) (2010) 3223-3230.

[95] M. Adeel, X. Song, Y. Wang, D. Francis, Y. Yang, Environmental impact of estrogens on human, animal and plant life: a critical review, Environ. Int. 99 (2017) 107-119. [96] F.-S. Zhang, Y.-F. Xie, X.-W. Li, D.-Y. Wang, L.-S. Yang, Z.-Q. Nie, Accumulation of steroid hormones in soil and its adjacent aquatic environment from a typical intensive vegetable cultivation of North China, Sci. Total Environ. 538 (2015) 423-430.

[97] Z. Fan, J. Hu, W. An, M. Yang, Detection and occurrence of chlorinated byproducts of bisphenol a, nonylphenol, and estrogens in drinking water of china: comparison to the parent compounds, Environ. Sci. Technol. 47 (19) (2013) 10841-10850.

[98] C. P. Silva, M. Otero, V. Esteves, Processes for the elimination of estrogenic steroid hormones from water: a review, Environ. Pollut. 165 (2012) 38-58.

[99] T. Iguchi, H. Watanabe, Y. Katsu, Application of ecotoxicogenomics for studying endocrine disruption in vertebrates and invertebrates, Environ. Health Perspect. 114 (Suppl 1) (2005) 101-105.

[100] K. Caballero-Gallardo, J. Olivero-Verbel, J. L Freeman, Toxicogenomics to evaluate endocrine disrupting effects of environmental chemicals using the zebrafish model, Curr. Genomics 17 (6) (2016) 515-527.

[101] L. S. Lee, N. Carmosini, S. A. Sassman, H. M. Dion, M. S. Sepulveda, Agricultural contributions of antimicrobials and hormones on soil and water quality, Advances in Agronomy 93 (2007) 1-68. 
[102] E. P. Kolodziej, T. Harter, D. L. Sedlak, Dairy wastewater, aquaculture, and spawning fish as sources of steroid hormones in the aquatic environment, Environ. Sci. Technol. 38 (23) (2004) 6377-6384.

[103] J. K. Leet, L. S. Lee, H. E. Gall, R. R. Goforth, S. Sassman, D. A. Gordon, J. M. Lazorchak, M. E. Smith, C. T. Jafvert, M. S. Sepúlveda, Assessing impacts of land-applied manure from concentrated animal feeding operations on fish populations and communities, Environ. Sci. Technol. 46 (24) (2012) 13440-13447.

[104] E. F. Orlando, A. S. Kolok, G. A. Binzcik, J. L. Gates, M. K. Horton, C. S. Lambright, L. E. Gray Jr, A. M. Soto, L. J. Guillette Jr, Endocrine-disrupting effects of cattle feedlot effluent on an aquatic sentinel species, the fathead minnow, Environ. Health Perspect. 112 (3) (2004) 353.

[105] J. Li, Current status and prospects for in-feed antibiotics in the different stages of pork production-A review, Asian-Australas J Anim Sci 30 (12) (2017) 1667.

[106] S. A. McEwen, P. J. Fedorka-Cray, Antimicrobial use and resistance in animals, Clin. Infect. Dis. 34 (Supplement_3) (2002) S93-S106.

[107] P. A. Thacker, Alternatives to antibiotics as growth promoters for use in swine production: a review, J. Anim. Sci. Biotechno. 4 (1) (2013) 35.

[108] F. A. Omonijo, L. Ni, J. Gong, Q. Wang, L. Lahaye, C. Yang, Essential oils as alternatives to antibiotics in swine production, Animal Nutrition 4 (2) (2018) 126-136. [109] D. B. Anderson, V. McCracken, R. Aminovi, J. Simpson, R. Mackie, M. Verstegen, H. Gaskins, Gut microbiology and growth-promoting antibiotics in swine, Pig News and Information 20 (1999) 115-122.

[110] P. Blanchard, M. Ellis, C. Maltin, G. Falkous, J. Harris, D. Mantle, Effect of growth promoters on pig muscle structural protein and proteolytic enzyme levels in vivo and in vitro, Biochimie 75 (10) (1993) 839-847. 
[111] H. S. Hurd, S. Malladi, A stochastic assessment of the public health risks of the use of macrolide antibiotics in food animals, Risk Analysis: An International Journal 28 (3) (2008) $695-710$.

[112] F. W. DI, Antibiotc resistance key to understanding effects to curtail antibiotics in poultry, in, https://www.biomin.net/en/articles/antibiotic-resistance-key-to-understandingefforts-to-curtail-antibiotics-in-poultry/, 2018.

[113] D. F. Maron, T. J. Smith, K. E. Nachman, Restrictions on antimicrobial use in food animal production: an international regulatory and economic survey, Globalization and health 9 (1) (2013) 48 .

[114] G. Pradella, A. Anadón, V. Klose, R. Plail, M. Mohnl, G. Schatzmayr, P. Spring, C. Montesissa, F. Calini, Workshop III: 2006 EU ban on antibiotics as feed additives: Consequences and perspectives, J. Vet. Pharmacol. Ther. 29 (1) (2006) 41-46.

[115] D. o. A. a. D. o. Health, Australia's First National Antimicrobial Resistance Strategy 2015-2019, in, https://www.amr.gov.au/resources/australias-first-national-antimicrobialresistance-strategy-2015-2019-progress-report, 2015.

[116] W. H. Organization, Stop using antibiotics in healthy animals to prevent the spread of antibiotic resistance, in, http://www.who.int/news-room/detail/07-11-2017-stop-usingantibiotics-in-healthy-animals-to-prevent-the-spread-of-antibiotic-resistance, 2017. [117] A. Lekagul, Patterns of antibiotic use in global pig production: a systematic review, Vet. Anim. Sci. (2019) 100058.

[118] H. M. 1. Jensen, Health management with reduced antibiotic use-experiences of a Danish pig vet, Anim. Biotechnol. 17 (2) (2006) 189-194.

[119] T. Laine, M. Yliaho, V. Myllys, T. Pohjanvirta, M. Fossi, M. Anttila, The effect of antimicrobial growth promoter withdrawal on the health of weaned pigs in Finland, Prev. Vet. Med. 66 (1-4) (2004) 163-174. 
[120] C. De Lange, J. Pluske, J. Gong, C. Nyachoti, Strategic use of feed ingredients and feed additives to stimulate gut health and development in young pigs, Livestock Science 134 (1-3) (2010) 124-134.

[121] M. D. Subramaniam, I. H. Kim, Clays as dietary supplements for swine: a review, J. Anim. Sci. Biotechno. 6 (1) (2015) 38.

[122] M. V. Suiryanrayna, J. Ramana, A review of the effects of dietary organic acids fed to swine, J. Anim. Sci. Biotechno. 6 (1) (2015) 45.

[123] W. Oliver, J. Wells, Lysozyme as an alternative to growth promoting antibiotics in swine production, J. Anim. Sci. Biotechno. 6 (1) (2015) 35.

[124] S. F. Liao, M. Nyachoti, Using probiotics to improve swine gut health and nutrient utilization, Animal Nutrition (2017)

[125] R. Dowarah, A. Verma, N. Agarwal, The use of Lactobacillus as an alternative of antibiotic growth promoters in pigs: a review, Animal Nutrition 3 (1) (2017) 1-6.

[126] Z. Zeng, X. Xu, Q. Zhang, P. Li, P. Zhao, Q. Li, J. Liu, X. Piao, Effects of essential oil supplementation of a low-energy diet on performance, intestinal morphology and microflora, immune properties and antioxidant activities in weaned pigs, Anim. Sci. J. 86 (3) (2015) 279285.

[127] K. Walia, H. Argüello, H. Lynch, F. C. Leonard, J. Grant, D. Yearsley, S. Kelly, G. Duffy, G. E. Gardiner, P. G. Lawlor, Effect of strategic administration of an encapsulated blend of formic acid, citric acid, and essential oils on Salmonella carriage, seroprevalence, and growth of finishing pigs, Prev. Vet. Med. 137 (2017) 28-35.

[128] C. Yang, M. Chowdhury, Y. Huo, J. Gong, Phytogenic compounds as alternatives to infeed antibiotics: potentials and challenges in application, Pathogens 4 (1) (2015) 137-156. [129] R. E. Isaacson, Development of vaccines for bacterial diseases using recombinant DNA technology, Avian Dis. (1986) 28-36. 
[130] K. Hoelzer, L. Bielke, D. P. Blake, E. Cox, S. M. Cutting, B. Devriendt, E. ErlacherVindel, E. Goossens, K. Karaca, S. Lemiere, Vaccines as alternatives to antibiotics for food producing animals. Part 2: new approaches and potential solutions, Vet. Res. 49 (1) (2018) 70.

[131] M. Laanen, D. Persoons, S. Ribbens, E. de Jong, B. Callens, M. Strubbe, D. Maes, J. Dewulf, Relationship between biosecurity and production/antimicrobial treatment characteristics in pig herds, Vet. J. 198 (2) (2013) 508-512.

[132] B. Gleeson, A. Collins, Under what conditions is it possible to produce pigs without using antimicrobials?, Animal Production Science 55 (12) (2015) 1424-1431.

[133] S. Ribbens, J. Dewulf, F. Koenen, K. Mintiens, L. De Sadeleer, A. de Kruif, D. Maes, A survey on biosecurity and management practices in Belgian pig herds, Prev. Vet. Med. 83 (3-4) (2008) 228-241.

[134] A. Backhans, M. Sjölund, A. Lindberg, U. Emanuelson, Biosecurity level and health management practices in 60 Swedish farrow-to-finish herds, Acta. Vet. Scand. 57 (1) (2015) 14.

[135] M. Zhang, Y.-S. Liu, J.-L. Zhao, W.-R. Liu, L.-Y. He, J.-N. Zhang, J. Chen, L.-K. He, Q.-Q. Zhang, G.-G. Ying, Occurrence, fate and mass loadings of antibiotics in two swine wastewater treatment systems, Sci. Total Environ. 639 (2018) 1421-1431.

[136] S. Combalbert, V. Bellet, P. Dabert, N. Bernet, P. Balaguer, G. Hernandez-Raquet, Fate of steroid hormones and endocrine activities in swine manure disposal and treatment facilities, Water Res. 46 (3) (2012) 895-906.

[137] Y. Li, G. Zhu, W. J. Ng, S. K. Tan, A review on removing pharmaceutical contaminants from wastewater by constructed wetlands: design, performance and mechanism, Sci. Total Environ. 468 (2014) 908-932. 
[138] J. Laurent, M. Casellas, C. Dagot, Heavy metals biosorption on disintegrated activated sludge: Description of a new equilibrium model, Chem. Eng. J. 164 (1) (2010) 63-69.

[139] H. Hamid, C. Eskicioglu, Fate of estrogenic hormones in wastewater and sludge treatment: A review of properties and analytical detection techniques in sludge matrix, Water Res. 46 (18) (2012) 5813-5833.

[140] D. A. d. Oliveira, A. Pinheiro, M. d. Veiga, T. C. Alves, Occurrence and mobility of antimicrobials and hormones in Oxisol with application of swine slurry, RBRH 21 (2) (2016) 391-400.

[141] D. Park, Y.-S. Yun, J. M. Park, The past, present, and future trends of biosorption, Biotechno. Bioproce Eng. 15 (1) (2010) 86-102.

[142] M. Fomina, G. M. Gadd, Biosorption: current perspectives on concept, definition and application, Bioresour. Technol. 160 (2014) 3-14.

[143] M. Carballa, F. Omil, J. M. Lema, M. a. Llompart, C. García-Jares, I. Rodríguez, M. Gomez, T. Ternes, Behavior of pharmaceuticals, cosmetics and hormones in a sewage treatment plant, Water Res. 38 (12) (2004) 2918-2926.

[144] S.-F. Yang, C.-F. Lin, A. Y.-C. Lin, P.-K. A. Hong, Sorption and biodegradation of sulfonamide antibiotics by activated sludge: experimental assessment using batch data obtained under aerobic conditions, Water Res. 45 (11) (2011) 3389-3397.

[145] Y. Luo, W. Guo, H. H. Ngo, L. D. Nghiem, F. I. Hai, J. Zhang, S. Liang, X. C. Wang, A review on the occurrence of micropollutants in the aquatic environment and their fate and removal during wastewater treatment, Sc. Total Environ. 473 (2014) 619-641.

[146] M. B. Ahmed, J. L. Zhou, H. H. Ngo, W. Guo, Adsorptive removal of antibiotics from water and wastewater: progress and challenges, Sci. Total Environ. 532 (2015) 112-126.

[147] J. Tolls, Sorption of veterinary pharmaceuticals in soils: a review, Environ. Sci.

Technol. 35 (17) (2001) 3397-3406. 
[148] D. Cheng, H. H. Ngo, W. Guo, Y. Liu, S. W. Chang, D. D. Nguyen, L. D. Nghiem, J.

Zhou, B. Ni, Anaerobic membrane bioreactors for antibiotic wastewater treatment:

performance and membrane fouling issues, Bioresour. Technol. (2018)

[149] J. Xu, G.-P. Sheng, Y. Ma, L.-F. Wang, H.-Q. Yu, Roles of extracellular polymeric substances (EPS) in the migration and removal of sulfamethazine in activated sludge system, Water Res. 47 (14) (2013) 5298-5306.

[150] J. O. Tijani, O. O. Fatoba, L. F. Petrik, A review of pharmaceuticals and endocrinedisrupting compounds: sources, effects, removal, and detections, Water, Air, Soil Pollut. 224 (11) (2013) 1770 .

[151] N. H. Tran, T. Urase, H. H. Ngo, J. Hu, S. L. Ong, Insight into metabolic and cometabolic activities of autotrophic and heterotrophic microorganisms in the biodegradation of emerging trace organic contaminants, Bioresour. Technol. 146 (2013) 721-731.

[152] E. Müller, W. Schüssler, H. Horn, H. Lemmer, Aerobic biodegradation of the sulfonamide antibiotic sulfamethoxazole by activated sludge applied as co-substrate and sole carbon and nitrogen source, Chemosphere 92 (8) (2013) 969-978.

[153] K. Fischer, M. Majewsky, Cometabolic degradation of organic wastewater micropollutants by activated sludge and sludge-inherent microorganisms, Appl. Microbiol. Biotechnol. 98 (15) (2014) 6583-6597.

[154] J. Chen, S. Xie, Overview of sulfonamide biodegradation and the relevant pathways and microorganisms, Sci. Total Environ. 640 (2018) 1465-1477.

[155] Y. Chen, H. Zhang, Y. Luo, J. Song, Occurrence and dissipation of veterinary antibiotics in two typical swine wastewater treatment systems in east China, Environ. Monit. Assess. 184 (4) (2012) 2205-2217. 
[156] L. Liu, C. Liu, J. Zheng, X. Huang, Z. Wang, Y. Liu, G. Zhu, Elimination of veterinary antibiotics and antibiotic resistance genes from swine wastewater in the vertical flow constructed wetlands, Chemosphere 91 (8) (2013) 1088-1093.

[157] X. Song, R. Liu, L. Chen, T. Kawagishi, Comparative experiment on treating digested piggery wastewater with a biofilm MBR and conventional MBR: simultaneous removal of nitrogen and antibiotics, Front. Environ. Sci. Eng. 11 (2) (2017) 11.

[158] L. N. Nguyen, F. I. Hai, J. Kang, W. E. Price, L. D. Nghiem, Removal of emerging trace organic contaminants by MBR-based hybrid treatment processes, Int. Biodeterior. Biodegrad. 85 (2013) 474-482.

[159] Y. Suzuki, A. Kubota, T. Furukawa, K. Sugamoto, Y. Asano, H. Takahashi, T. Sekito, Y. Dote, Y. Sugimoto, Residual of $17 \beta$-estradiol in digestion liquid generated from a biogas plant using livestock waste, J. Hazard. Mater. 165 (1-3) (2009) 677-682.

[160] J. Sipma, B. Osuna, N. Collado, H. Monclús, G. Ferrero, J. Comas, I. Rodriguez-Roda, Comparison of removal of pharmaceuticals in MBR and activated sludge systems, Desalination 250 (2) (2010) 653-659.

[161] N. Prado, J. Ochoa, A. Amrane, Biodegradation by activated sludge and toxicity of tetracycline into a semi-industrial membrane bioreactor, Bioresour. Technol. 100 (15) (2009) 3769-3774.

[162] Y. Xiao, H. Yaohari, C. De Araujo, C. C. Sze, D. C. Stuckey, Removal of selected pharmaceuticals in an anaerobic membrane bioreactor (AnMBR) with/without powdered activated carbon (PAC), Chem. Eng. J. 321 (2017) 335-345.

[163] L. Goswami, R. V. Kumar, S. N. Borah, N. A. Manikandan, K. Pakshirajan, G. Pugazhenthi, Membrane bioreactor and integrated membrane bioreactor systems for micropollutant removal from wastewater: A review, J. Water Process Eng. 26 (2018) 314328. 
[164] H. Wu, J. Zhang, H. H. Ngo, W. Guo, Z. Hu, S. Liang, J. Fan, H. Liu, A review on the sustainability of constructed wetlands for wastewater treatment: design and operation, Bioresour. Technol. 175 (2015) 594-601.

[165] P. N. Carvalho, J. L. Araújo, A. P. Mucha, M. C. P. Basto, C. M. R. Almeida, Potential of constructed wetlands microcosms for the removal of veterinary pharmaceuticals from livestock wastewater, Bioresour. Technol. 134 (2013) 412-416.

[166] L. Liu, Y.-h. Liu, Z. Wang, C.-x. Liu, X. Huang, G.-f. Zhu, Behavior of tetracycline and sulfamethazine with corresponding resistance genes from swine wastewater in pilot-scale constructed wetlands, J. Hazard. Mater. 278 (2014) 304-310.

[167] M. Scholz, B. h. Lee, Constructed wetlands: a review, Int. J. Environ. Stud. 62 (4) (2005) 421-447.

[168] A. Kurt, B.K. Mert, N. Özengin, Ö. Sivrioğlu, T. Yonar, Treatment of antibiotics in wastewater using advanced oxidation processes (AOPs), Physico-Chemical Wastewater Treatment and Resource Recovery, (2017) 175.

[169] R. Anjali, S. Shanthakumar, Insights on the current status of occurrence and removal of antibiotics in wastewater by advanced oxidation processes, J. Environ. Manage. 246 (2019) $51-62$.

[170] V. Homem, L. Santos, Degradation and removal methods of antibiotics from aqueous matrices-a review, J. Environ. Manage. 92 (2011) 2304-2347.

[171] I. Oller, S. Malato, J. Sánchez-Pérez, Combination of advanced oxidation processes and biological treatments for wastewater decontamination - a review, Sci. Total Environ. 409 (2011) 4141-4166.

[172] M.B. Ahmed, J.L. Zhou, H.H. Ngo, W. Guo, N.S. Thomaidis, J. Xu, Progress in the biological and chemical treatment technologies for emerging contaminant removal from wastewater: a critical review, J. Hazard. Mater. 323 (2017) 274-298. 
[173] G. Lofrano, R. Pedrazzani, G. Libralato, M. Carotenuto, Advanced oxidation processes for antibiotics removal: a review, Curr. Org. Chem. 21 (2017) 1054-1067.

[174] W. Ben, Z. Qiang, X. Pan, M. Chen, Removal of veterinary antibiotics from sequencing batch reactor (SBR) pretreated swine wastewater by Fenton's reagent, Water Res. 43 (2009) $4392-4402$.

[175] S. Doğruel, F. Germirli - Babuna, I. Kabdaşlı, G. Insel, D. Orhon, Effect of stream segregation on ozonation for the removal of significant COD fractions from textile wastewater, Journal of Chemical Technology \& Biotechnology: International Research in Process, Environmental \& Clean Technology, 78 (2003) 6-14.

[176] Z. Qiang, J.J. Macauley, M.R. Mormile, R. Surampalli, C.D. Adams, Treatment of antibiotics and antibiotic resistant bacteria in swine wastewater with free chlorine, J. Agric. Food Chem., 54 (2006) 8144-8154.

[177] H. Schaar, M. Clara, O. Gans, N. Kreuzinger, Micropollutant removal during biological wastewater treatment and a subsequent ozonation step, Environ. Pollut. 158 (2010) 13991404.

[178] W. Ben, Z. Qiang, X. Pan, Y. Nie, Degradation of veterinary antibiotics by ozone in swine wastewater pretreated with sequencing batch reactor, J. Environ. Eng. 138 (2011) 272277. 